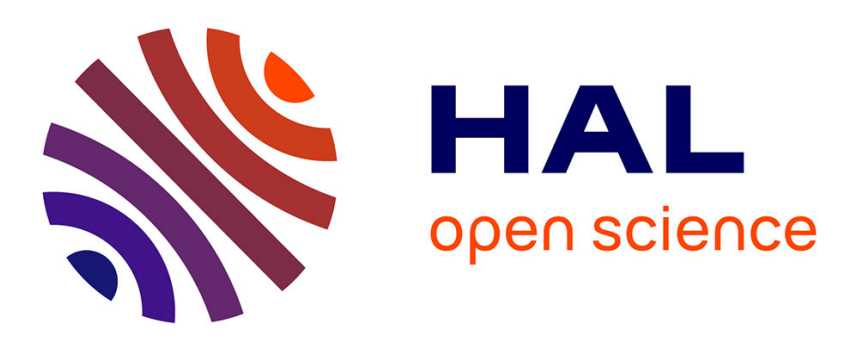

\title{
Boosted $\mathrm{Cr}(\mathrm{VI})$ sorption coupled reduction from aqueous solution using quaternized algal/alginate@PEI beads
}

Yue Zhang, Yayuan Mo, Vincent Thierry, Catherine Faur, Guibal Eric

\section{- To cite this version:}

Yue Zhang, Yayuan Mo, Vincent Thierry, Catherine Faur, Guibal Eric. Boosted Cr(VI) sorption coupled reduction from aqueous solution using quaternized algal/alginate@PEI beads. Chemosphere, 2021, 281, pp.130844. 10.1016/j.chemosphere.2021.130844 . hal-03241019

\section{HAL Id: hal-03241019 https://hal.mines-ales.fr/hal-03241019}

Submitted on 28 May 2021

HAL is a multi-disciplinary open access archive for the deposit and dissemination of scientific research documents, whether they are published or not. The documents may come from teaching and research institutions in France or abroad, or from public or private research centers.
L'archive ouverte pluridisciplinaire HAL, est destinée au dépôt et à la diffusion de documents scientifiques de niveau recherche, publiés ou non, émanant des établissements d'enseignement et de recherche français ou étrangers, des laboratoires publics ou privés. 


\title{
Boosted Cr(VI) sorption coupled reduction from aqueous solution using quaternized algal/alginate@PEI beads
}

\author{
Yue Zhang ${ }^{\mathrm{a}, \mathrm{b}}$, Yayuan Mo ${ }^{\mathrm{a}, \mathrm{b}}$, Thierry Vincent ${ }^{\mathrm{a}}$, Catherine Faur ${ }^{\mathrm{b}}$, Eric Guibal ${ }^{\mathrm{a}, *}$ \\ ${ }^{\text {a }}$ PCH, IMT Mines Ales, 6, Avenue de Clavières, 30319, Alès Cedex, France \\ ${ }^{\mathrm{b}}$ IEM, Institut Européen des Membranes, Univ. Montpellier, CNRS, ENSCM, 300 Avenue Du Prof. Emile Jeanbrau, 34090, Montpellier, France
}

\begin{abstract}
A B S T R A C T
APEI beads (algal/alginate-PEI) were quaternized for enhancing the sorption of $\mathrm{Cr}(\mathrm{VI})$ (Q-APEI). The readily reduction of $\mathrm{Cr}(\mathrm{VI})$ into $\mathrm{Cr}(\mathrm{III})$ in acidic solution and in the presence of organic material constitute an additional phenomenon to be taken into account for the removal of $\mathrm{Cr}(\mathrm{VI})$ by Q-APEI. The optimal $\mathrm{pH}$ value for both the sorption and reduction of $\mathrm{Cr}(\mathrm{VI})$ was close to 2. The sorption isotherm was well described by the Sips model in batch system; the experimental maximum $\mathrm{Cr}(\mathrm{VI})$ sorption capacity of Q-APEI was $334 \mathrm{mg} \mathrm{Cr}(\mathrm{VI}) \mathrm{g}^{-1}$, including a reduction yield close to $25 \%$. The pseudo-second-order kinetic model (PSORE) and the Yan model fit the uptake kinetics and breakthrough curves, in a fixed-bed system with circulation or single-path modes, respectively. The mechanism of reduction-assisted sorption allows boosting the global removal of chromate. Furthermore, the testing of $\mathrm{Cr}(\mathrm{VI})$ for three successive sorption and desorption cycles shows the remarkable stability of the sorbent for $\mathrm{Cr}(\mathrm{VI})$ removal. The $\mathrm{Cr}(\mathrm{VI})$ sorption coupled reduction mechanism and interactions between the sorbent and $\mathrm{Cr}(\mathrm{VI})$ were further explained using Fourier transform infrared spectroscopy (FTIR), X-ray photoelectron spectroscopy (XPS), scanning electron microscopy (SEM), and energy dispersive spectroscopy (EDS).
\end{abstract}

Keywords:

Alga/alginate beads

Polyethylenimine

Quaternary ammonium group

Hexavalent chromium

Sorption-coupled reduction

\section{Introduction}

Although chromium naturally occurs in the earth's mantle and can be transferred into water bodies, anthropogenic activities lead to substantial and critical increases in the concentration of this metal in surface water but also in underground water resources. Cast iron, metallurgy and electroplating are among the industrial activities that generate the most chromate contamination (Arris et al., 2016). Commonly, chromium exists in aqueous system as two major oxidation states: $\mathrm{Cr}(\mathrm{VI})$ and $\mathrm{Cr}(\mathrm{III})$ (Gorny et al., 2016). Cr(VI) species has been regarded as a critical contaminant due to its high toxicity (e.g., mutagenicity, oncogenicity and genotoxicity) to human body and detrimental accumulation in the food chain (Saha et al., 2011). On the other hand, $\mathrm{Cr}$ (VI) can be readily reduced by electron donor to form $\mathrm{Cr}(\mathrm{III})$, which is less toxic and can be hydrolyzed (to form, for example, $\mathrm{Cr}(\mathrm{OH})_{2}^{+}$and $\mathrm{Cr}$ $(\mathrm{OH})^{2+}$ ) and further precipitated (Saha and Orvig, 2010; Fenti et al., 2020).

Bioremediation techniques gain advantages on causing little side effect to natural environment, especially on making use of industrial or agricultural wastes (Jobby et al., 2018). So far, considerable research efforts have been devoted to the elimination of $\mathrm{Cr}(\mathrm{VI})$ pollution through biosorption, namely the multi-interactions between materials of biological origin with $\mathrm{Cr}(\mathrm{VI})$ species (Pradhan et al., 2017). Widely-used biosorbent materials, such as raw or retreated materials (e.g., algal biomass, rye husk, seed pods and fruits) (Altun et al., 2016; Wang et al., 2016; Ajmani et al., 2019; Kumar et al., 2020), polysaccharide-based materials (e.g., alginate, chitosan and lignocellulose) (Miretzky and Cirelli, 2010; Yan et al., 2017a; Tekay et al., 2019) showed respectable sorption capacities for $\mathrm{Cr}(\mathrm{VI})$ due to their high porosity, stability, and surface reactivity. The mechanism for $\mathrm{Cr}(\mathrm{VI})$ biosorption mainly involves reduction-coupled sorption, in which the biosorbent serves as an electron donor, the anionic chromate can be easily bound once the reactive groups on biosorbent surface are protonated under acidic environment.

As mentioned before, algal biomass materials revealed unique environmental, ecological and economic benefits as a category of green resource. In terms of composition, algal biomass possess specific molecules such as alginates, phytochelatins, sulfated polysaccharides with hydroxyl, carboxyl and sulfate as functional groups (Shanab et al., 2012). The main derivatives from algal biomass, including alginic acid

\footnotetext{
* Corresponding author. IMT-Mines Ales, Polymers Composites and Hybrids, 6 avenue de Clavières, 30319, Alès cedex, France.

E-mail addresses: yue.zhang@mine-ales.fr (Y. Zhang), moyayuan110@163.com (Y. Mo), Thierry.Vincent@mines-ales.fr, thierry.vincent@mines-ales.fr (T. Vincent), catherine.faur@univ-montp2.fr (C. Faur), Eric.Guibal@mines-ales.fr (E. Guibal).
} 
and its salts (e.g., sodium, calcium and ammonium alginate), were conventionally used as food additives (i.e., stabilizers, emulsifiers and thickeners), as well as chemical reagents (i.e., dispersing, gelling and hydration agents) in all walks of life (Szabó et al., 2020). However, due to the unfavorable mechanical stability, formability, and permeability of algae biomass, simply ionically cross-linked algal hydrogels were not suitable in the application of biosorption. Recently, an emerging algal/alginate-based material, which was synthesized by the combination of alga, sodium alginate and polyethyleneimine, via double-crosslinking process (calcium ionotropic gelation and amine-glutaraldehyde crosslinking) was designed in the form of beads (noted as APEI) (Wang et al., 2019). The APEI beads were characterized by the homogeneous presence of hydroxyl, carboxylate groups (on alga and alginate), and amine groups (on PEI) (primary, secondary and tertiary amine groups as well as ceto-imine groups after glutaraldehyde cross-linking). Due to the presence of a wide variety of chemical groups on the structural chains, this material can be readily functionalized. Various derivative were synthesized (by grafting sulfonic, amidoxime or phosphorylated groups) to enhance specific sorption properties for transition metal (e.g., Mo) (Wei et al., 2021), metalloids (e.g., As) (Hamza et al., 2020a) and rare earth elements (e.g., Sr, Nd and U) (Wei et al., 2019, 2021; Hamza et al., 2020b) in terms of sorption capacity or selectivity. These previous studies were dedicated to valuable or hazardous metal ions; these metal ions are not subject to strong reduction under mild conditions. It would be useful investigating the behavior of this type of sorbent for the uptake of metal ions that are sensitive to reduction phenomena (such as chromate). Therefore, investigating the impact of reduction both at the level of reactive groups and on overall removal performance is of critical importance. The reduction phenomenon is usually associated to the oxidation of the sorbent; this oxidation of the support may induce a degradation of the structure of the sorbent and a progressive loss in sorption performance. This new study provides information on the stability of this sorbent under drastic conditions.

The current work further extends the applications of quaternized alginate-based PEI-crosslinked beads (noted as Q-APEI) to $\mathrm{Cr}(\mathrm{VI})$ sorption and reduction. The Q-APEI is aimed to boost the $\mathrm{Cr}(\mathrm{VI})$ reduction through the electron donor effect provided by the negatively charged chlorine ion (counter anion of grafted quaternary ammonium group), in addition to the specific reduction of chromate through organic matter in acidic solution. The quaternary ammonium groups were grafted to enhance the density of active sites and total cationic charge on the sorbent surface. Indeed, chromate being present in mild-acidic solutions under the form of anionic species, increasing the cationic behavior of APEI is supposed to improve metal binding (in addition to the already described reduction effect). The removal of $\mathrm{Cr}(\mathrm{VI})$ is studied taking into account $\mathrm{Cr}(\mathrm{VI})$ depletion in the solution but also in evaluating the removal of $\mathrm{Cr}$ element (including $\mathrm{Cr}(\mathrm{III})$ ) to follow the impact of metal reduction. Investigating both $\mathrm{Cr}(\mathrm{VI})$ and $\mathrm{Cr}(\mathrm{III})$ concentrations in the solution allows following the sorption and reduction contributions more finely.

The first part of the study focuses on the evaluation of the effect of $\mathrm{pH}$ on sorption and reduction performance, and the selection of optimum $\mathrm{pH}$. In a second step, the sorption isotherms, uptake kinetics, and breakthrough curves are investigated in different systems (batch and fixed-bed column modes) to comprehensively analyze $\mathrm{Cr}(\mathrm{VI})$ removal by Q-APEI beads in aqueous solution, comparing with original APEI beads as reference material. The reversibility and reusability of $\mathrm{Cr}(\mathrm{VI})$ sorption onto Q-APEI beads are studied to evaluate the recycling ability of the sorbent for practical water treatment. Finally, the sorption mechanism between $\mathrm{Cr}(\mathrm{VI})$ and the functional groups on the surface of the Q-APEI is proposed, based on a series of supplementary characterizations (i.e., FTIR, XPS, SEM, and SEM-EDS).

\section{Materials and methods}

\subsection{Materials and reagents}

Laminaria digitata biomass came from Setalg (Pleubian, France) and was preprocessed by rinsing, grinding and sieving. Sodium alginate (namely Manugel GMB) was provided by DuPont (Landerneau, France; now JRS Rettenmaier). Branched polyethylenimine (PEI, 50\%, w/w), glutaraldehyde solution (GA, 50\%) and poly(ethyleneglycol) diglycidyl ether were purchased from Sigma-Aldrich (Taufkirchen, Germany). $\mathrm{K}_{2} \mathrm{Cr}_{2} \mathrm{O}_{7}, \mathrm{Na}_{2} \mathrm{CO}_{3}$ and $\mathrm{CaCl}_{2} \cdot 2 \mathrm{H}_{2} \mathrm{O}, \mathrm{HCl}, \mathrm{NaOH}$, methanol and $\mathrm{HCOOH}$ were supplied by Chem-lab NV (Zedelgem, Belgium). $\mathrm{K}_{2} \mathrm{Cr}_{2} \mathrm{O}_{7}$ was used as a source of $\mathrm{Cr}(\mathrm{VI})$ solution. All solutions were prepared using deionized water. The rest of chemical reagents, including isopropyl alcohol from Carlo Erba (France), dimethylformamide (DMF) were supplied by PanReac AppliChem ITW (Chicago, USA) and glycidyltrimethylammonium chloride was pruchased from Fluka AG (Buchs, Switzerland).

\subsection{Preparation of sorbents}

The quaternization of algal/alginate@PEI beads were prepared according to the protocols previously described by Wang et al. (2019) and Hamza et al. (2020c) with slight modifications.

\subsubsection{Synthesis of algal/alginate@PEI beads (APEI)}

Briefly, $L$. digitata algal biomass (i.e., $18.75 \mathrm{~g}$ ) was fully mixed with $750 \mathrm{~g}$ of $\mathrm{Na}_{2} \mathrm{CO}_{3}$ solution $(1 \%, \mathrm{w} / \mathrm{w})$ under agitation, and then the mixture was stored at $50{ }^{\circ} \mathrm{C}$ for $12 \mathrm{~h}$. After cooling, an alginate solution (4\%, w/w) was added to the algal mixture (final mass: $1 \mathrm{~kg}$ ). Ten grams of PEI solution $(50 \%, \mathrm{w} / \mathrm{w})$ was then added to the mixture under strong agitation. Subsequently, the mixture was added dropwise into a 1-L volume of cross-linking and gelling agent (i.e., containing $10 \mathrm{~mL}$ of $\mathrm{HCOOH}, 5 \mathrm{~mL}$ of GA $\left(50 \%\right.$, w/w) and $10 \mathrm{~g}$ of $\left.\mathrm{CaCl}_{2} \cdot 2 \mathrm{H}_{2} \mathrm{O}\right)$, via a thin nozzle. The algal/alginate-PEI (APEI) beads were maintained under agitation for $24 \mathrm{~h}$ in the crosslinking/gelation solution before being washed and freeze-dried at $-101{ }^{\circ} \mathrm{C}$ for $24 \mathrm{~h}$.

\subsubsection{Quaternization of algal/alginate@PEI beads (Q-APEI)}

The first step in the process consisted of a complementary crosslinking: Poly(ethyleneglycol) diglycidyl ether $(3 \mathrm{~mL})$ was added to isopropanol $(90 \mathrm{~mL}$ ) before introducing $5 \mathrm{~g}$ of APEI beads. The suspension was refluxed at $20 \pm 1{ }^{\circ} \mathrm{C}$ for $4 \mathrm{~h}$ under agitation (agitation speed: 300 $\mathrm{rpm}$ ). The cross-linked (cAPEI) beads were then washed with water and methanol, and freeze-dried at $-101{ }^{\circ} \mathrm{C}$ for $24 \mathrm{~h}$.

Glycidyltrimethylammonium chloride $(10 \mathrm{~g})$ was mixed with $140 \mathrm{~mL}$ DMF: $\mathrm{H}_{2} \mathrm{O}(1: 1, \mathrm{v} / \mathrm{v})$ mixture in a three-necked flask under gentle stirring. Next, $5 \mathrm{~g}$ of cAPEI beads were added to the suspension and the flask was refluxed at $73^{\circ} \mathrm{C}$ in a water bath for $24 \mathrm{~h}$ under agitation (agitation speed: $300 \mathrm{rpm}$ ). Finally, the quaternized cAPEI (Q-APEI) were washed with hot water and methanol before being freeze-dried.

\subsection{Sorption study in batch systems}

Batch sorption experiments were applied to investigate $\mathrm{Cr}(\mathrm{VI})$ sorption performance and optimize the sorption capability of sorbents through the study of $\mathrm{pH}$ effect, sorbent dosage, metal concentration, and reaction time. Every sample solution was filtered after collecting, using filter papers (Ø: $25 \mathrm{~mm}$, Prat-Dumas, France).

For the study of $\mathrm{pH}$, every flask was loaded with $12.5 \pm 0.3 \mathrm{mg}$ (d.w.) of sorbent and filled with a fixed volume (i.e., $25 \mathrm{~mL}$; V, L) of chromate solution $\left(\mathrm{C}_{0}: 100 \mathrm{mg} \mathrm{Cr} \mathrm{L}^{-1}\right)$ (i.e., sorbent dosage: $\left.\mathrm{SD}: 0.5 \mathrm{~L}^{-1}\right)$, at different $\mathrm{pH}$ values (in the range 1-7, adjusted with $\mathrm{HCl}$ and/or $\mathrm{NaOH}$ solution), and shaken (speed: $200 \mathrm{rpm}$ ) for $48 \mathrm{~h}$, at $20 \pm 1{ }^{\circ} \mathrm{C}$. The $\mathrm{pH}$ was not controlled during sorption but the final $\mathrm{pH}$ was monitored at the end of the experiment. The qualitative and quantitative analysis of TCr 
(total $\mathrm{Cr}$ ) and $\mathrm{Cr}(\mathrm{VI})$ in filtrated samples $\left(\mathrm{C}_{\mathrm{eq}}, \mathrm{mg} \mathrm{Cr} \mathrm{L}^{-1}\right.$ or $\mathrm{mmol} \mathrm{Cr} \mathrm{L}^{-1}$ ) were analyzed by ICP-AES and spectrophotometry, respectively. Total chromium was analyzed by an inductively coupled plasma atomic emission spectrometer ICP-AES ACTIVA M (Horiba Jobin Yvon, Longjumeau, France). The specific concentration of $\mathrm{Cr}(\mathrm{VI})$ was obtained by the diphenylcabazide method (DPC (Ahmad et al., 2019)); after reaction with diphenylcarbazide the absorbance was measured using an UV-VIS spectrophotometer UV-1650PC (Shimadzu Corp., Kyoto, Japan). The sorption capacity $\left(\mathrm{q}_{\mathrm{eq}}, \mathrm{mmol} \mathrm{Cr}^{-1}\right.$ ) was obtained by the mass balance equation: $\mathrm{q}_{\mathrm{eq}}=\left(\mathrm{C}_{0}-\mathrm{C}_{\mathrm{eq}}\right) \times \mathrm{V} / \mathrm{L}$.

For the sorption isotherm, $12.5 \pm 0.3 \mathrm{mg}$ (d.w.) of sorbents were contacted with $25 \mathrm{~mL}$ of $\mathrm{Cr}(\mathrm{VI})$ ion solution at different initial concentrations $\left(\mathrm{C}_{0}\right.$, ranging from 5 to $\left.500 \mathrm{mg} \mathrm{L}^{-1}\right)$ for $48 \mathrm{~h}$, at $20 \pm 1^{\circ} \mathrm{C}$. The $\mathrm{pH}$ value of solution was initially set at 2 and the flasks were simultaneously shaken at $200 \mathrm{rpm}$.

\subsection{Column process}

\subsubsection{Uptake kinetics on recirculation mode}

For uptake kinetics, different parameters of sorption process using QAPEI were investigated (i.e., flow rate and initial $\mathrm{Cr}(\mathrm{VI})$ concentration). Fixed-bed column sorption experiments were performed using a set of consecutive input equipment (as shown in Figure S1a). The $\mathrm{Cr}(\mathrm{VI})$ solution was pumped through a flow system composed of a peristaltic pump (Ismatec ISM404B, USA), sorbent loader, and water container. The sorbent loader was a laboratory PS tube (Ø: $16 \mathrm{~mm}$; height: $9 \mathrm{~cm}$ ), which was filled with $500 \pm 3 \mathrm{mg}$ (d.w.) of beads (i.e., height: $63.5 \pm$ $0.3 \mathrm{~mm}$ ). Two plastic disks were kept at the bottom and the top of the loaded beads to stabilize the beads in the column and prevent the beads from leakage. At a preset flow rate $\left(25\right.$ or $\left.50 \mathrm{~mL} \mathrm{~min}^{-1}\right), 1 \mathrm{~L}$ of $\mathrm{Cr}(\mathrm{VI})$ solution ( 100 or $200 \mathrm{mg} \mathrm{L}^{-1}$ ) was continuously transported by peristaltic pumps through the column. Four milliliters of samples were taken out from the water containers and filtrated at desired time intervals over a total period of $2880 \mathrm{~min}$ (i.e., $48 \mathrm{~h}$ ). The uptake dynamic curves were subsequently plotted between ratio of instant and initial $\mathrm{Cr}(\mathrm{VI})$ concentration $\left(\mathrm{C}_{\mathrm{t}} / \mathrm{C}_{0}\right)$ in solution $v$ s. time (min).

\subsubsection{Breakthrough curves on single-path mode}

Low flow rates (i.e., 2 or $4 \mathrm{~mL} \mathrm{~min}^{-1}$ ) were studied for breakthrough behavior of the fixed-bed column sorption process. In a single-path flow system (as shown in Figure S1b), the $\mathrm{Cr}(\mathrm{VI})$ solution was continuously fed to the fixed-bed column, which was loaded with $0.5 \mathrm{~g}$ sorbents, but without recirculation process. The effluent solution of fixed-bed column was collected and filtered at desired time intervals.

\subsubsection{Desorption and reuse studies}

Three cycles of sorption-desorption studies were carried out in fixedbed system with recirculation mode, to investigate metal desorption and the reusability of Q-APEI. For each cycle, Q-APEI beads (i.e., $0.25 \mathrm{~g}$ ) were contacted with $500 \mathrm{~mL}$ of $100 \mathrm{mg} \mathrm{Cr} \mathrm{L}^{-1}$ solution for $60 \mathrm{~h}$. Afterwards, the Q-APEI were rinsed with deionized water for $5 \mathrm{~min}$ before applying the desorption process. The Cr-loaded Q-APEI were reacted with $500 \mathrm{~mL}$ eluent solution (i.e., $0.2 \mathrm{~mol} \mathrm{~L}^{-1} \mathrm{NaOH}$ ) for $8 \mathrm{~h}$. Then the QAPEI beads were rinsed for reuse (for 3 cycles) under the same experimental conditions; the sorption rate and desorption efficiency were further calculated. After each step of sorption-desorption cycle, the QAPEI beads were washed with demineralized water until the $\mathrm{pH}$ value of solution was neutral.

\subsection{Characterization of sorbents}

Fourier-transform infrared spectroscopy (FTIR) was performed in the range $4000-400 \mathrm{~cm}^{-1}$ using a Bruker VERTEX70 spectrometer (Bruker, Germany) equipped with an ATR (Attenuated Total Reflectance tool). The morphology and structure of sorbents were characterized using an environmental scanning electron microscope (SEM) Quanta FEG 200
(FEI France, Thermo Fisher Scientific, Mérignac, France), coupled with an Oxford Inca 350 energy dispersive X-ray (EDX) micro-analyzer (Oxford Instruments France, Saclay, France). The $\mathrm{pH}$ point of zero charge $\left(\mathrm{pH}_{\mathrm{PZC}}\right)$ of the beads was approached applying the so-called $\mathrm{pH}$ drift method (Zyoud et al., 2019). A fixed amount of sorbent (i.e., $0.05 \mathrm{~g}$ ) was added to $25 \mathrm{~mL}$ of $0.1 \mathrm{M} \mathrm{NaCl}$ solution at different initial $\mathrm{pH}$ values $\left(\mathrm{pH}_{0}\right.$, in the range of 1-12). The suspension was agitated (150 rpm) for $72 \mathrm{~h}$, at $20 \pm 1{ }^{\circ} \mathrm{C}$. The equilibrium $\mathrm{pH}\left(\mathrm{pH}_{\mathrm{eq}}\right)$ was recorded and plotted against $\mathrm{pH}_{0}$; therefore, the $\mathrm{pH}_{\mathrm{PZC}}$ corresponds to the point at which $\mathrm{pH}_{\mathrm{eq}}=\mathrm{pH}_{0}$. The bulk density and apparent porosity of the beads were characterized by pycnometer measurements using ethanol as the soaking agent.

\subsection{Modeling and statistical analysis}

Sorption isotherms were fitted by the Langmuir, the Freundlich and the Sips models, while pseudo-first order rate equation (PFORE), pseudo-second order rate equation (PSORE) and intraparticle diffusion equation (IPDE) were used to describe the uptake kinetic. Thomas model and Yan model were applied to the breakthrough curve study. All the equations and models are summarized in the Supplementary Information section (Eqs. S1-S11).

Akaike's Information Criterion (AIC) is one of the versatile error function analysis to evaluate and normalize the quality of fitting models (which have different number of parameters) to experimental results (Bonilla-Petriciolet et al., 2017). The highest fitting model of the experimental data corresponds to the lowest value of AIC. The values of AIC are given by the following equation (Eq. (1)):

$\mathrm{AIC}=\mathrm{N} \cdot \ln \left(\frac{\mathrm{SSR}}{\mathrm{N}}\right)+2 \mathrm{P}+\frac{2 \mathrm{P}(\mathrm{P}+1)}{\mathrm{N}-\mathrm{P}-1}$

where $\mathrm{N}$ denotes the number of experimental samples, while $\mathrm{P}$ is the number of parameters in every model; SSR represents the sum of squared residuals, which can be calculated by Eq. (2):

$\operatorname{SSR}=\sum_{\mathrm{t}=0}^{\mathrm{t}}\left(\mathrm{q}_{\mathrm{t}}-\mathrm{q}_{\mathrm{t}, \mathrm{cal}}\right)^{2}$

where $\mathrm{q}_{\mathrm{t}}$ and $\mathrm{q}_{\mathrm{t}, \mathrm{cal}}$ correspond to the sorption capacity calculated from the experimental data and the model, respectively.

Note: all the experiments were carried out in duplicate or triplicate; the average values and standard deviations of data were calculated and embodied in the figures.

\section{Results and discussions}

\subsection{Physical characteristics of sorbents}

The porous structure of Q-APEI beads and APEI beads is shown in Table S1 (obtained by SEM and EDS analysis), respectively; their physical characteristics are reported in Table S2. Compared with APEI beads (i.e., $3.11 \pm 0.03 \mathrm{~mm}$, d.w.), Q-APEI beads exhibit a smaller average size (i.e., $2.98 \pm 0.04 \mathrm{~mm}$, d.w.) and a near $0.6 \%$ weight loss per unit weight (data no shown). Although there is no significant difference between the average bulk density of Q-APEI bead (i.e., $0.058 \pm 0.003 \mathrm{~g} \mathrm{~cm}^{-3}$ ) and that of APEI bead (i.e., $0.061 \pm 0.004 \mathrm{~g} \mathrm{~cm}^{-3}$ ), it is notable that the porosity of Q-APEI (i.e., $80.73 \pm 0.85 \%$ ) greatly improved comparing to that of APEI (i.e., $58.87 \pm 0.62 \%$ ). Higher porosity normally implies a larger surface area, which makes it possible for Q-APEI to a better sorption performance of $\mathrm{Cr}(\mathrm{VI})$ in the following study.

\subsection{Batch process}

\subsection{1. $p H$ effect}

The $\mathrm{pH}$ value of the aqueous system critically influences not only the transformation of hexavalent chromium species, but also the effective 
charge of sorbent surface. Previously, it has been confirmed that acidic condition is favorable to the binding of $\mathrm{Cr}(\mathrm{VI})$ anionic species on protonated amine groups, especially at strong acidity (i.e., pH 2) (Gorny et al., 2016). A similar $\mathrm{Cr}(\mathrm{VI})$ sorption pattern is observed in this study. Fig. 1 compares the pH effect on the sorption of $\mathrm{Cr}(\mathrm{VI})$ by both Q-APEI and APEI. Notably, the sorption capacity of TCr (i.e., total mass of $\mathrm{Cr}$ ) was quantified by ICP-AES while the sorption capacity of $\mathrm{Cr}(\mathrm{VI})$ was determined by the DPC method. Therefore, the recapitulative mass balance equation of chromium (i.e., $\mathrm{TCr}=\mathrm{Cr}(\mathrm{VI})+\mathrm{Cr}(\mathrm{III})$ ) reveals that chromate reduction takes place in acidic solution and tends to be negligible at moderately acidic or neutral $\mathrm{pH}$ values. Also, both APEI and Q-APEI sorbents achieve maximal sorption capacities of $\mathrm{Cr}(\mathrm{VI})$ (i.e., 190 and $146 \mathrm{mg} \mathrm{g}^{-1}$ ) at this $\mathrm{pH}$ (i.e., 2) before the gradual decline at higher $\mathrm{pH}$ values, which is confirmed by the EDX spectra. Specifically, the EDX spectra (as presented in Table S1) for Q-APEI after Cr(VI) sorption shows the $\mathrm{Cr}$ mass proportions (semi-quantitative evaluation) under every $\mathrm{pH}$ value (i.e., pH 2: $23.6 \%$, pH 4: $14.1 \%$ and $\mathrm{pH}$ 6: $12.7 \%$ ). Synchronized variation trend is noticed for the results of $\mathrm{TCr}$ sorption capacities under

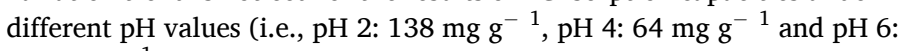
$53 \mathrm{mg} \mathrm{g}^{-1}$ ). Indeed, the highly protonated amine groups inclined to combine with chromate oxyanions (i.e., $\mathrm{HCrO}_{4}^{-}, \mathrm{CrO}_{4}^{2-}$ and $\mathrm{Cr}_{2} \mathrm{O}^{-}$) at low pH value (Deng and Bai, 2003; Tian et al., 2015), meanwhile, the electrostatic attraction between the carboxyl groups and chromate species is strengthened (Duranoğlu and Beker, 2015).

Given that many bio-derived materials are capable of inducing the reduction reactions of $\mathrm{Cr}(\mathrm{VI})$ to $\mathrm{Cr}(\mathrm{III})$ under various experimental
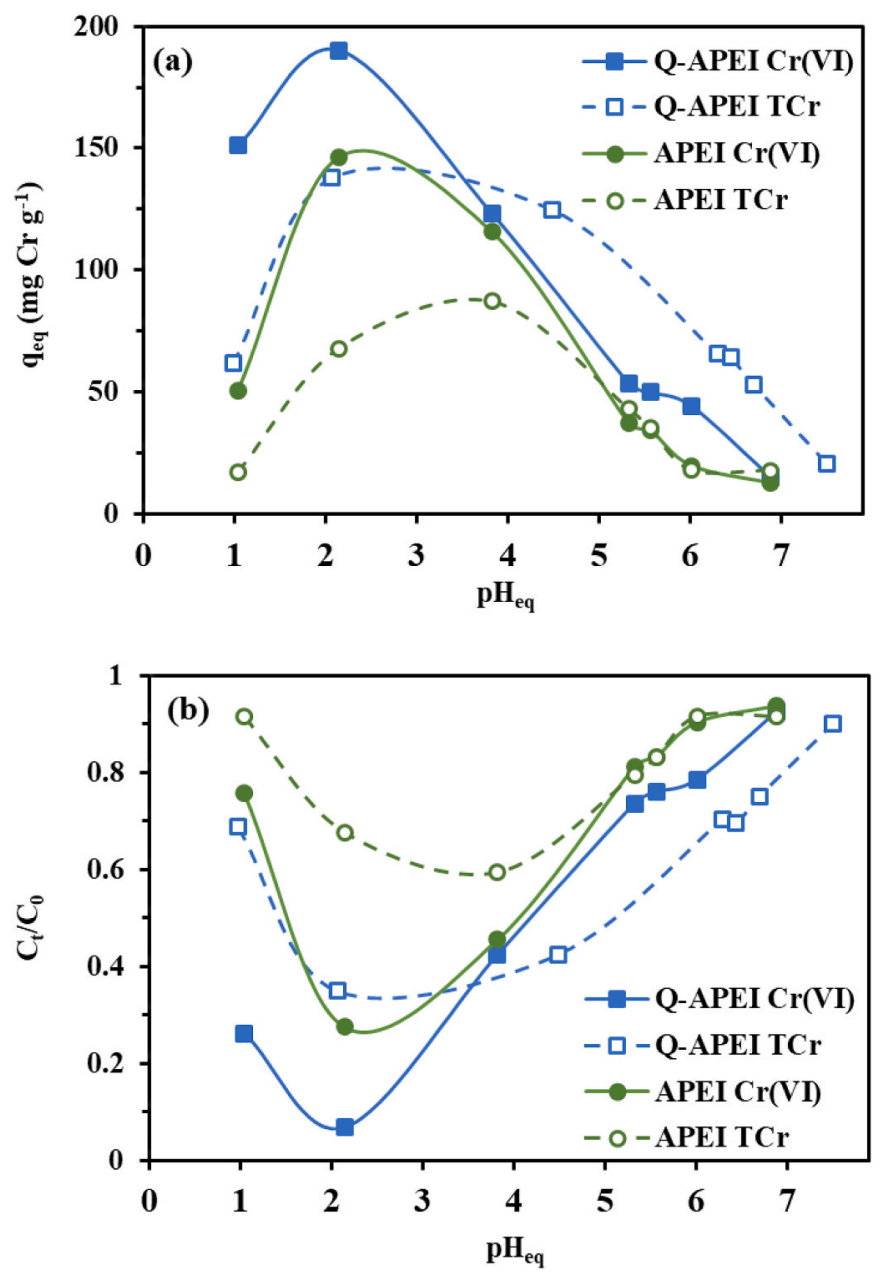

Fig. 1. Effect of $\mathrm{pH}$ on the $\mathrm{Cr}(\mathrm{VI})$ and $\mathrm{TCr}$ sorption using APEI and Q-APEI: $\mathrm{q}_{\mathrm{eq}}$ (a) and $\mathrm{C}_{\mathrm{t}} / \mathrm{C}_{0}$ (b) $\left(\mathrm{C}_{0}: 100 \mathrm{mg} \mathrm{Cr}(\mathrm{VI}) \mathrm{L}^{-1}\right.$; sorbent dosage: $0.5 \mathrm{~g} \mathrm{~L}^{-1}$; contact time: $48 \mathrm{~h}$; shaking speed: $200 \mathrm{rpm}$; T: $20 \pm 1{ }^{\circ} \mathrm{C}$ ). conditions (Park et al., 2007; Sun et al., 2010), this phenomenon deserves further discussion. Park et al. (2005) reported that Cr(VI) could be completely reduced to $\mathrm{Cr}$ (III) in aqueous solution by fungi and seaweed at pH 2. Furthermore, Xu et al. (2019) confirmed that biochar showed a higher conversion rate of $\mathrm{Cr}(\mathrm{VI})$ to $\mathrm{Cr}(\mathrm{III})$ at $\mathrm{pH} 2$, comparing to that at $\mathrm{pH}$ 4. On the other hand, similar kind of polyethylenimine/alginate-based foams (not quaternized) presented a different trend: the $\mathrm{Cr}(\mathrm{VI})$ reduction into $\mathrm{Cr}(\mathrm{III})$ was relatively weak between $\mathrm{pH} 2$ and 6 , but substantial reduction was observed at a lower pH (i.e., 0.5) (Mo et al., 2019). Above-mentioned discussions indicated that apart from the common effect of sorption and complexation, the interaction between chromate and functional groups on surface or internal compartments of sorbents may involve complex and multiple reaction mechanisms. For example, reduction mechanisms may involve reactions such as in Eqs. (3)-(5), depending on $\mathrm{pH}$, metal concentration and metal speciation.

$\mathrm{HCrO}_{4}{ }^{-}+7 \mathrm{H}^{+}+3 \mathrm{e}^{-} \leftrightharpoons \mathrm{Cr}^{3+}+4 \mathrm{H}_{2} \mathrm{O}$

$\mathrm{Cr}_{2} \mathrm{O}_{7}^{2-}+14 \mathrm{H}^{+}+6 \mathrm{e}^{-} \leftrightharpoons 2 \mathrm{Cr}^{3+}+7 \mathrm{H}_{2} \mathrm{O}$

$\mathrm{CrO}_{4}{ }^{2-}+8 \mathrm{H}^{+}+3 \mathrm{e}^{-} \leftrightharpoons \mathrm{Cr}^{3+}+4 \mathrm{H}_{2} \mathrm{O}$

The speciation diagrams of $\mathrm{Cr}(\mathrm{VI})$ and $\mathrm{Cr}(\mathrm{III})$ under studied $\mathrm{pH}$ range of 1.0-7.0 are separately shown in Figure $\mathrm{S} 2$. Below pH 6.5, $\mathrm{HCrO}_{4}^{-}$is the predominant $\mathrm{Cr}(\mathrm{VI})$ species (over $75 \%$ ), with a small amount of $\mathrm{Cr}_{2} \mathrm{O}_{7}^{2-}$ species (less than 10\%). As $\mathrm{pH}$ increases above 4, divalent anionic $\mathrm{CrO}_{4}^{2-}$ species becomes to predominate, which may require more active sites for binding equivalent amount of chromium. Hereinto, $\mathrm{Cr}$ (III) species mainly exists as cationic chromium hydroxide species (e.g., $\mathrm{Cr}(\mathrm{OH})_{2}^{+}$). Additionally, the sorption capacities of $\mathrm{Cr}(\mathrm{VI})$ using Q-APEI surpass those of APEI under every selected $\mathrm{pH}$ value, likely due to the cationic nitrogen of grafted quaternary ammonium groups, which enhances the positive charge of sorbent surface and increases the density of reactive groups (Fang et al., 2007). This is consistent with the comparison from the $\mathrm{pH}_{\mathrm{PZC}}$ of original algal/alginate@PEI sorbent before and after quaternization (i.e., APEI and Q-APEI) (shown in Figure S3). That is, after modification, the $\mathrm{pH}_{\mathrm{PZC}}$ of Q-APEI (i.e., 7.2) was near 3 units higher than the original APEI sorbent (i.e., 4.2); the increase of the global positive charge on the sorbent surface favors the sorption of anionic species. The grafting of quaternary ammonium groups not only was ideal for binding more anionic chromate but also provided a wider $\mathrm{pH}$ range of protonation. Subsequently, Figure S4 contradistinguishes the $\mathrm{pH}$ shifts of $\mathrm{Cr}$ (VI) sorption using Q-APEI and APEI, respectively. It can be observed that below initial $\mathrm{pH}$ value of 2 , the equilibrium $\mathrm{pH}$ values of both sorbents barely changed in strong acidic environment. Afterwards, when initial $\mathrm{pH}$ value exceeds 3 , the equilibrium $\mathrm{pH}$ values of both sorbents slimly exceeded the initial $\mathrm{pH}$, probably due to the generation of alkaline chromium hydroxide species after $\mathrm{Cr}(\mathrm{VI})$ reduction.

\subsubsection{Sorption isotherms}

Sorption isotherms represent the distribution, at equilibrium, of the solute between the liquid phase (residual concentration, $\mathrm{C}_{\mathrm{eq}}$ ) and the solid phase (concentration on the sorbent or sorption capacity, $\mathrm{q}_{\mathrm{eq}}$ ), for different solute concentrations, at given temperature and $\mathrm{pH}$ (or environmental parameters such as ionic strength) (Liu et al., 2020). Three conventional equations (i.e., Langmuir, Freundlich and Sips models, Eqs. (S1-3)) are used for comparing different sorbents under identical experimental conditions and theoretical calculation. The Langmuir isotherm assumes that the monolayer-type sorption takes place at homogeneous surface sites, Freundlich isotherm, on the other hand, is more appropriate for describing multi-layer sorption on heterogeneous sorbent surface (Saadi et al., 2015; Gupta et al., 2017). Sips equation is a derived three-parameter isotherm model that combines the Langmuir and the Freundlich models. It is developed to predict the heterogeneity of the sorption systems, as well as to eliminate the restrictions when dealing with high metal concentrations (N'diaye et al., 2019). Usually, 
the Sips equation allows fitting more appropriately the most-curved section of the sorption isotherms (compared with the Langmuir equation). On the other hand, the Freundlich equation is a power-like function that rarely fits experimental profiles when a saturation plateau is observed. Based on the asymptotic trends observed in Fig. 2, it is logical that the Langmuir and the Sips equation best fit the experimental profiles. This is further confirmed by Table S3; the Sips equation provides better statistical criteria (i.e., $R^{2}$ and AIC) than the Langmuir equation. Additionally, in the case of $\mathrm{Cr}(\mathrm{VI})$ sorption using Q-APEI, the values of separation factor $\mathrm{R}_{\mathrm{L}}$ (Eq. S2b) lay between 0.01 and 0.54 for all studied $\mathrm{Cr}(\mathrm{VI})$ concentrations (data no shown), revealing the favorability of $\mathrm{Cr}$ (VI) sorption on Q-APEI beads.

Fig. 2 shows both $\mathrm{Cr}(\mathrm{VI})$ and $\mathrm{TCr}$ sorption isotherms for sorbents at pH 2 and their relevant curves (fitted by the Sips equation). The sorption isotherms for both $\mathrm{Cr}(\mathrm{VI})$ and $\mathrm{TCr}$ belong to a typical category of "convex upward" (Inglezakis et al., 2018; Al-Ghouti and Da'ana, 2020), namely begins with a steep slope, followed by a saturation plateau. In this study, the $\mathrm{q}_{\mathrm{eq}}$ values of both $\mathrm{Cr}(\mathrm{VI})$ and $\mathrm{TCr}$ (i.e., 380 and $248 \mathrm{mg}$ $\mathrm{g}^{-1}$ ) using Q-APEI largely exceed those of APEI (i.e., 238 and $164 \mathrm{mg}$ $\mathrm{g}^{-1}$ ) and other biomaterial sorbents listed in Table S4. Afterwards, the sorption efficiency of sorbent as a function of the initial $\mathrm{Cr}(\mathrm{VI})$ concentration (i.e., $\mathrm{C}_{0}: 5-400 \mathrm{mg} \mathrm{L}^{-1}$ ) (shown in Figure S5), reveals that Q-APEI was capable of removing more than $90 \% \mathrm{Cr}(\mathrm{VI})$ below initial concentration of $100 \mathrm{Cr} \mathrm{mg} \mathrm{L}^{-1}$. The grafting of quaternary ammonium groups substantially boosted the removal of $\mathrm{Cr}(\mathrm{VI})$ compared with APEI raw beads. The APEI sorbent possesses abundant hydroxyl group and carboxyl group, which are already favorable for binding $\mathrm{Cr}(\mathrm{VI})$. The quaternization process provides extra cationic quaternary ammonium groups for electrostatic attraction between $\mathrm{Cr}(\mathrm{VI})$ and cationic polymer groups. Moreover, based on the Pearson's theory, the hard acids prefer to react with hard bases meanwhile soft acids prefer to complex with soft bases (Ayers, 2005). Chromium is recognized to be a kind of hard acid therefore has strong affinity to hard bases like oxygen (in carboxylic-typed groups) or nitrogen (in amine-typed groups) (Tang et al., 2003). Noteworthy, the affinities coefficients $\mathrm{K}_{\mathrm{S}}\left(\mathrm{L} \mathrm{mg}^{-1}\right)$ showed an affinity almost 2 times higher on Q-APEI for $\mathrm{Cr}(\mathrm{VI})$ sorption than that of APEI, while there was an opposite trend for $\mathrm{TCr}$ sorption. As mentioned before, the sorption of TCr may involve $\mathrm{Cr}(\mathrm{VI})$ sorption coupled reduction and $\mathrm{Cr}(\mathrm{III})$ release. Therefore, the enhancement of sorption capacity may be also explained by the higher reduction of $\mathrm{Cr}$ (VI) by Q-APEI. Indeed, this assumption is also supported by the higher difference between $\mathrm{Cr}(\mathrm{VI})$ and $\mathrm{TCr}$ (i.e., the amount of $\mathrm{Cr}(\mathrm{III})$ ) of Q-APEI compared to that of APEI (i.e., 131 and $73 \mathrm{mg} \mathrm{g}^{-1}$ ).

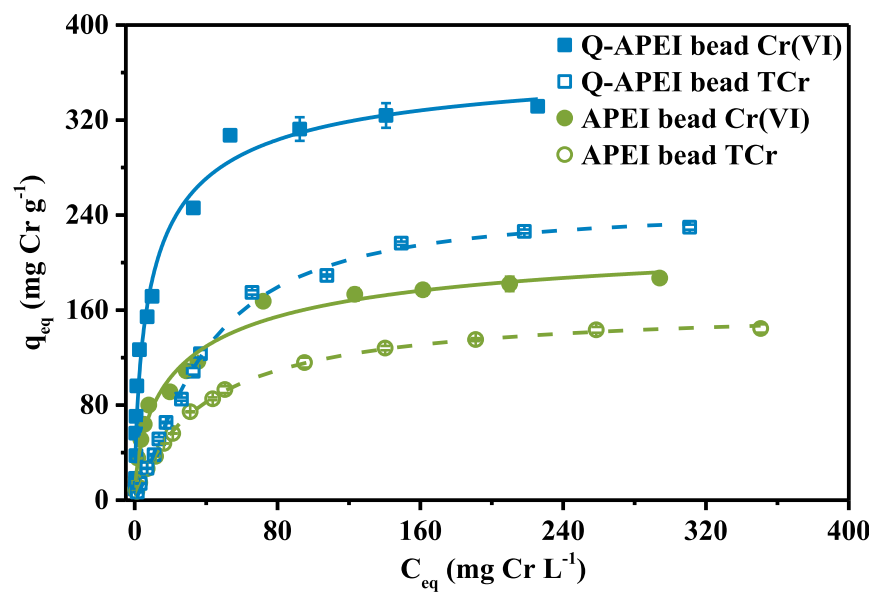

Fig. 2. Sorption isotherms of $\mathrm{Cr}(\mathrm{VI})$ and TCr using APEI and Q-APEI $\left(\mathrm{C}_{0}: 100\right.$ mg L ${ }^{-1}$; sorbent dosage: $0.5 \mathrm{~g} \mathrm{~L}^{-1}$; $\mathrm{pH}$ : 2; contact time: $48 \mathrm{~h}$; shaking speed: $200 \mathrm{rpm}$; T: $20 \pm 1{ }^{\circ} \mathrm{C}$. Lines (full lines-Cr(VI), dash lines-TCr) represent the modeling of sorption isotherms with the Sips equation and the parameters summarized in Table S3).

\subsection{Fixed-bed process on recirculation}

\subsubsection{Uptake kinetics}

In the fixed-bed column system, the reaction rate could be affected by various conditions, such as sorbent dosage, initial $\mathrm{Cr}(\mathrm{VI})$ concentration and flow rate (Xia et al., 2019). Fig. 3a displays, in parallel, the ratios of residual $\mathrm{Cr}(\mathrm{VI})$ and $\mathrm{TCr}$ to initial $\mathrm{Cr}(\mathrm{VI})$ concentration $\left(\mathrm{C}_{\mathrm{t}} / \mathrm{C}_{0}\right)$ as a function of reaction time during $\mathrm{Cr}(\mathrm{VI})$ sorption into a fixed-bed column packed with Q-APEI beads. The experiments were carried out on a recirculation mode with a preset $\mathrm{pH}$ value of effluent (i.e., $\mathrm{pH} 2$ ), while other conditions varied with initial $\mathrm{Cr}(\mathrm{VI})$ concentration (i.e., $\mathrm{C}_{0}$ : 100 or $200 \mathrm{mg} \mathrm{L}^{-1}$ ) and flow rate (i.e., F: 25 or $50 \mathrm{~mL} \mathrm{~min}^{-1}$ ). At F 50 $\mathrm{mL} \mathrm{min}^{-1}$, Q-APEI removed over $90 \%$ of $\mathrm{Cr}(\mathrm{VI})$ from aqueous solution at $\mathrm{C}_{0}: 100 \mathrm{mg} \mathrm{Cr} \mathrm{L}^{-1}$ and $69 \%$ at $\mathrm{C}_{0}: 200 \mathrm{mg} \mathrm{Cr} \mathrm{L}^{-1}$. Additionally, according to the proportional variations of $\mathrm{TCr}, \mathrm{Cr}(\mathrm{VI})$ and $\mathrm{Cr}(\mathrm{III})$ as a function of reaction time (under the different conditions shown in Figure S6), higher flow rate may facilitate the speed of $\mathrm{Cr}(\mathrm{VI})$ reduction (i.e., $\mathrm{Cr}(\mathrm{III})$ generation). In contrast, at the same flow rate, higher $\mathrm{Cr}(\mathrm{VI})$ reduction was obtained upon $\mathrm{C}_{0}$ : $200 \mathrm{mg} \mathrm{Cr} \mathrm{L}^{-1}$, the abundant amount of $\mathrm{Cr}(\mathrm{VI})$ ions in the solution enhances $\mathrm{Cr}(\mathrm{VI})$ reduction.

Kinetic study provides insights into the sorption pathway between $\mathrm{Cr}$ (VI) ions and Q-APEI beads. The steps that may control the uptake kinetics consist of mass transfer (including resistance to bulk liquid diffusion, film diffusion and intraparticle diffusion), thermal exchanges,
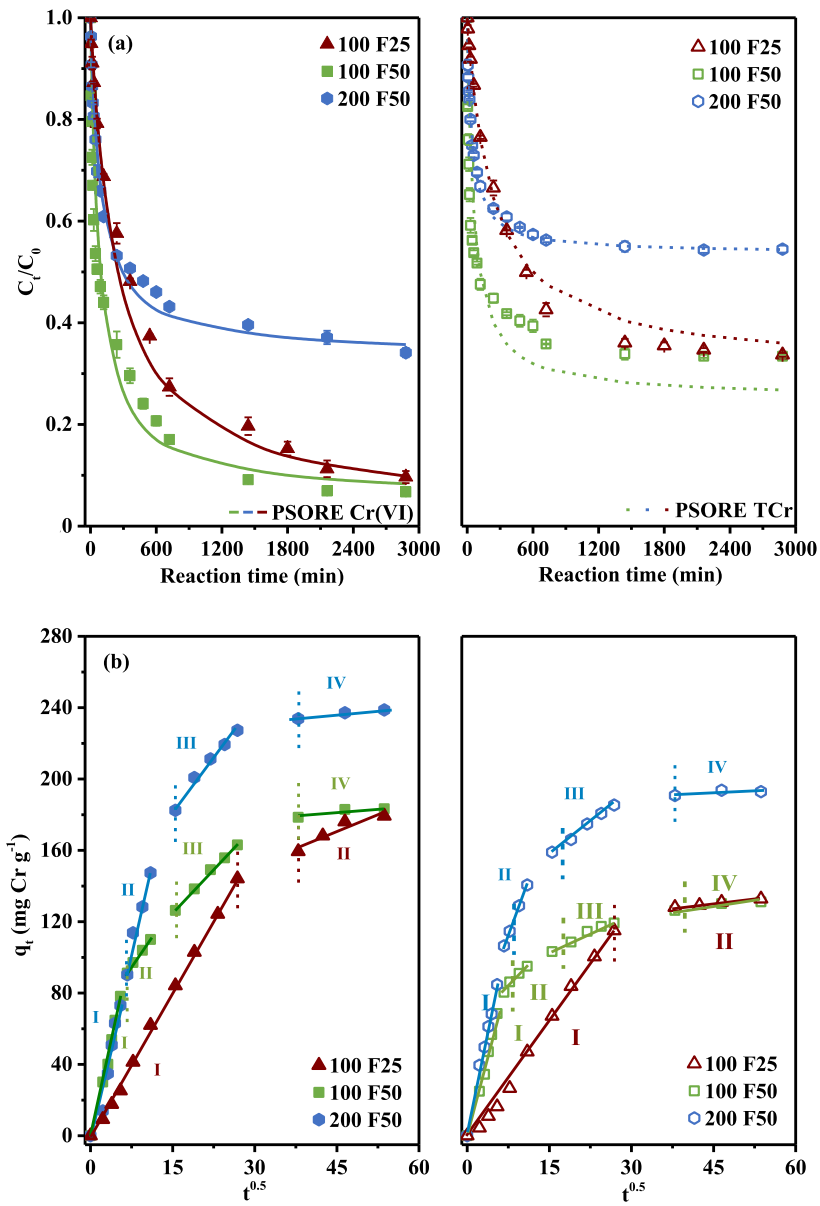

Fig. 3. Uptake kinetics of $\mathrm{Cr}(\mathrm{VI})$ and TCr sorption using Q-APEI in fixed-bed recirculation system (a), IPDE model (b) $\left(\mathrm{C}_{0}\right.$ : 100 or $200 \mathrm{mg} \mathrm{L}^{-1}$; F (flow rate): 25 or $50 \mathrm{~mL} \mathrm{~min}^{-1}$; sorbent mass: $0.5 \mathrm{~g}$; volume: $1 \mathrm{~L}$; $\mathrm{pH}$ : 2 ; contact time: $48 \mathrm{~h}$; T: $20 \pm 1{ }^{\circ} \mathrm{C}$. Lines (full lines-Cr(VI), dash lines-TCr) represent the modeling of kinetic profiles with the pseudo-second order rate equation using parameters from Table S5 for panel (a) and with the intraparticle diffusion equation using parameters from Table S6 for panel (b)). 
and/or proper chemical reactions. The kinetic profiles are characterized by a three-step sequence:

(i) the fast initial section (taking place within the first hours of contact) is associated with the sharp decrease (almost linear) of the concentration in the solution. This step corresponds with the rapid uptake on the reactive groups located at the surface or first primary external layers of the sorbent. This is usually within the first minutes of contact that the resistance to film diffusion is representing the predominant controlling mechanism.

(ii) the intermediary section is characterized by a gradual decrease of the $\mathrm{Cr}(\mathrm{VI})$ concentration (highest curvature of the kinetic profile); this step lasts up to $12-14 \mathrm{~h}$. The resistance to intraparticle diffusion controls this phase.

(iii) the last section is characterized by a very weak mass transfer (up to $48 \mathrm{~h}$ of contact). This is probably due to strong resistance to intraparticle diffusion in pores of thinner diameters.

In addition to these mechanisms oriented by resistance to diffusion, the proper reaction rate may also control the overall uptake kinetics (or at least contributes to this control associated with diffusion steps). The equations the most commonly used for describing reaction rates are the PFORE and the PSORE (see SI, Eqs. S4 and S5, respectively). These equations, initially designed for modeling homogeneous reactions, have been extended to the description of the kinetics in heterogeneous systems. To take into account the specificity of heterogeneous systems, the kinetic constants are considered as apparent rate coefficients (the proper effects of diffusional constraints being implicitly taken into account in the coefficients). Table S5 summarizes the parameters of the models (in addition to the statistical criteria for their comparative evaluation). The table clearly shows that the PSORE gives a better fit of experimental profiles; this is consistent with many studies focused on $\mathrm{Cr}(\mathrm{VI})$ sorption onto biosorbents (Mungasavalli et al., 2007; Arim et al., 2019). The good fitting degree of PSORE is supported not only by two error indicators, $\mathrm{R}^{2}$ and AIC, but also by the good agreements between experimental and calculated sorption capacities, $\mathrm{q}_{\mathrm{eq}, \exp }$ and $\mathrm{q}_{\mathrm{eq}, 1}$. The solid lines in Fig. $3 \mathrm{a}$ represent the PSORE fits. The modeling of kinetic profiles is frequently associated to sorption systems involving chemisorption mechanisms (Zhang et al., 2019). However, this conclusion was recently largely debated by several papers (Simonin, 2016; Hubbe et al., 2019), which reported the strong incidence of the choice of experimental data on the fitting of kinetic profiles and the hazardous conclusions that may derive from inappropriate experimental choices. More precisely, Hubbe et al. (2019) concluded that frequently the best fitting of kinetics by the PSORE may be explained, under selected experimental conditions, by a sorption kinetically controlled by the resistance to intraparticle diffusion. Their interpretation is clearly consistent with the kinetic steps (ii) and (iii).

Moreover, the apparent rate coefficients $\left(\mathrm{k}_{1}\right.$ and $\left.\mathrm{k}_{2}\right)$ for PFORE and

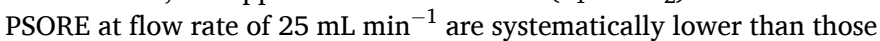
at the higher flow rate (i.e., $50 \mathrm{~mL} \mathrm{~min}^{-1}$ ). This observation is consistent with the former discussion about Figure S6, namely high flow rate accelerates the dispersing rate of $\mathrm{Cr}(\mathrm{VI})$ ions among the packed Q-APEI beads. The acceleration of the flow rate (or superficial velocity) directly influences the resistance to diffusion in the film surrounding sorbent particles.

Previous observation highlights the contribution of the resistance to intraparticle diffusion as the main rate-limiting factor of $\mathrm{Cr}(\mathrm{VI})$ sorption onto biomaterials (Pholosi et al., 2020; Zhang et al., 2020). When plotting sorption capacity against the square root of time, the $\mathrm{Cr}(\mathrm{VI})$ sorption kinetic curves at F50 could be divided into four linear sections (shown in Fig. 3b):

(I) start with a rapid and no rate-limiting $\mathrm{Cr}(\mathrm{VI})$ transfer from bulk solution to the liquid film covered on the surface of Q-APEI;
(II) then a slowdown transfer of $\mathrm{Cr}(\mathrm{VI})$ ions from liquid film into QAPEI surface;

(III) later the intraparticle diffusion of $\mathrm{Cr}(\mathrm{VI})$ ions onto the internal of Q-APEI through pore or surface diffusion;

(IV) the final equilibrium state.

At F25, there is only one step before reaching equilibrium. As shown in Table $\mathrm{S} 6$, the rate constant $\left(\mathrm{k}_{\mathrm{id}}\right)$ and diffusivity $\left(\mathrm{D}_{\mathrm{i}}\right)$ of intraparticle diffusion are obtained from the well-described intraparticle diffusion equation model (IPDE, Eq. S6a). For $\mathrm{Cr}(\mathrm{VI})$ sorption, the average $\mathrm{k}_{\mathrm{id}}$ values of section I, II and III (i.e., 14.39 and $7.32 \mathrm{mg} \mathrm{g}^{-1} \mathrm{~min}^{-0.5}$ ) at F50 are both higher than that (i.e., $5.47 \mathrm{mg} \mathrm{g}^{-1} \mathrm{~min}^{-0.5}$ ) at F25. Based on the results, high flow rate improves the external film diffusion, which, in turn, favors the intraparticle diffusion. Significantly, the $k_{i d}$ of every section can well describe the former kinetics profiles. Indeed, taking $\mathrm{Cr}$ (VI) sorption at $\mathrm{C}_{0}: 100 \mathrm{mg} \mathrm{L}^{-1}$ at $\mathrm{F} 50$ as an example, the $\mathrm{k}_{\mathrm{id}, 1}$ is over 3 times higher than $k_{i d, 2}$ and $k_{i d, 3}$, revealing a nearly not rate-limiting step in the first $30 \mathrm{~min}$. The reason that the $\mathrm{k}_{\mathrm{id}}$ values of the $\mathrm{TCr}$ sorption are lower than the corresponding $\mathrm{k}_{\mathrm{id}}$ values of the $\mathrm{Cr}(\mathrm{VI})$ sorption is that the later involves the contribution of $\mathrm{Cr}(\mathrm{VI})$ reduction. In the further discussion about diffusivity coefficient $\left(D_{i}\right.$, Eq. S6b), it is noteworthy that $D_{i}$ values lying in the range of $10^{-5}$ to $10^{-13} \mathrm{~cm}^{2} \mathrm{~s}^{-1}$ means that the intraparticle diffusion predominates as a rate-limiting step, particularly in the case of chemisorption reaction (Yakout and Elsherif, 2010). Herein, the values of $D_{i}$ (i.e., $16.67 \times 10^{-5}$ and $16.08 \times 10^{-5} \mathrm{~cm}^{2} \mathrm{~s}^{-1}$ ) in section I at both F25 and F50 are not included in this effective domain. This is another evidence that the intraparticle diffusion that occurs after the film mass transfer (i.e., section I) is rate-limiting and may involve contributions of chemical reactions.

\subsubsection{Sorption-desorption study}

Subsequently, the reusability of Q-APEI beads was investigated in Figure S7, the Q-APEI showed favorable performances (i.e., $\mathrm{q}_{\mathrm{eq}}$ and $\mathrm{Cr}$ (VI) desorption efficiency) for $\mathrm{Cr}(\mathrm{VI})$ sorption (and reduction) from aqueous solution during three successive cycles of sorption-desorption. The desorption efficiency decreases along sorbent recycling. This is probably due to the progressive saturation of the reactive groups and the incomplete desorption of $\mathrm{Cr}(\mathrm{VI})$ and/or $\mathrm{Cr}(\mathrm{III})$. Whereas, there were subtle differences between $\mathrm{Cr}(\mathrm{VI})$ and $\mathrm{TCr}$ after each desorption process, indicating that the species formed at the surface of the sorbent is most probably the $\mathrm{Cr}(\mathrm{VI})$-complex rather than the $\mathrm{Cr}(\mathrm{III})$-complex. Similarly, Dong et al. (2013) reported that soluble Cr(III) end-products was mostly detected in the aqueous solution after $\mathrm{Cr}(\mathrm{VI})$ biosorption by Bacillus cereus strain. Another explanation to the decrease of sorption and desorption performance may concern the progressive degradation of the reactive groups of the sorbent, which may be due to their oxidation by chromate (resulting into $\mathrm{Cr}(\mathrm{VI})$ conversion to $\mathrm{Cr}(\mathrm{III})$ ). However, the FT-IR characterization of the sorbent (as shown in below Figure S8), after sorption/desorption sequence, shows that the material is not significantly modified and the oxidation of reactive groups may be neglected.

\subsection{Fixed-bed process on single path}

In industrial wastewater treatment, sorbents are normally packed into fixed-bed system with a single-pass mode. In this case, the efficiency of the process can be strongly affected by the flow rate. To gain more insight, breakthrough curves under different flow rates (i.e., F: 2 or $4 \mathrm{~mL}$ $\min ^{-1}$ ) are depicted by plotting $\mathrm{C}_{\mathrm{t}} / \mathrm{C}_{0} v s$. time (shown in Fig. 4 ) and all the corresponding parameters (calculated by Eqs. S9-13) are given in Table S7, namely the critical points corresponding to times of breakthrough $\left(\mathrm{t}_{\mathrm{b}}\right)$ and saturation $\left(\mathrm{t}_{\mathrm{s}}\right)$. Several conclusions are drawn to describe the pattern of the breakthrough curves as follows: 


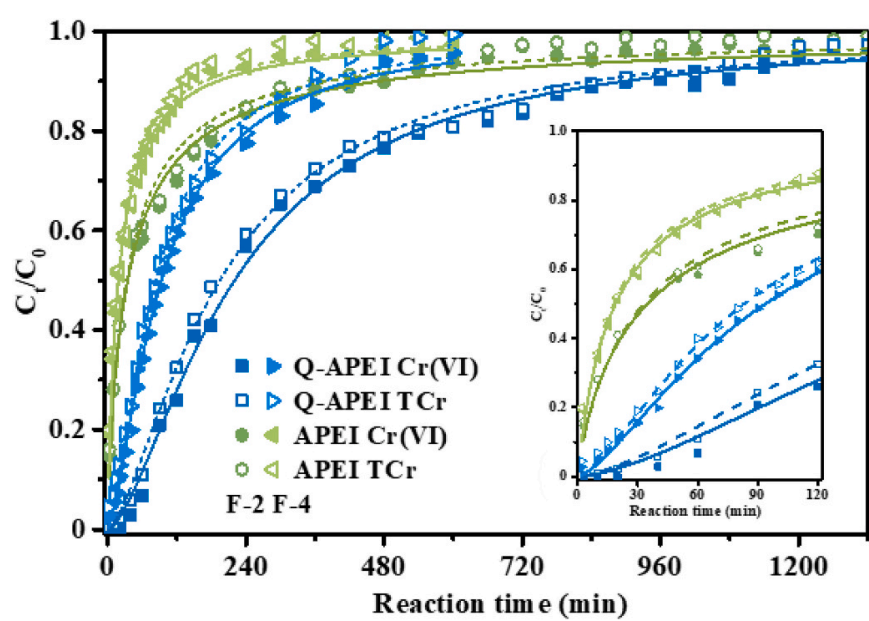

Fig. 4. Breakthrough curves of $\mathrm{Cr}(\mathrm{VI})$ and TCr sorption using APEI and Q-APEI in fixed-bed single path system $\left(\mathrm{C}_{0}: 100 \mathrm{mg} \mathrm{L}^{-1}\right.$; $\mathrm{F}$ (flow rate): 2 or $4 \mathrm{~mL} \mathrm{~min}^{-1}$; sorbent mass: $0.5 \mathrm{~g}$; volume: $1 \mathrm{~L}$; $\mathrm{pH}$ : 2 ; $\mathrm{T}: 20 \pm 1{ }^{\circ} \mathrm{C}$. Lines (full lines-Cr(VI), dash lines-TCr) represent the modeling with the Yan equation using parameters from Table S8).

(i) Q-APEI shows higher performances of $\mathrm{Cr}(\mathrm{VI})$ retention compared with APEI while considering the saturation time, regardless of the flow rate (i.e., $t_{s}$ values of Q-APEI near twice over those of APEI).

(ii) The total amount of sorbed $\mathrm{Cr}(\mathrm{VI})$ decreases with increasing the flow rate, due to the fact that the sorbents are not fully saturated $\left(\mathrm{C}_{\mathrm{eq}} \neq \mathrm{C}_{0}\right)$.

(iii) The flat curve (i.e., low slope) at lower flow rate owing to the sufficient contact time was provided for the reaction between $\mathrm{Cr}$ (VI) ions and sorbents. It is noteworthy that the $\mathrm{C}_{t} / \mathrm{C}_{0}$ (i.e., $\mathrm{Cr}(\mathrm{VI})$ retention rate) using Q-APEI was just 0.25 while the APEI already reached 0.69 in the first $120 \mathrm{~min}$ at $\mathrm{F} 2$.

In this study, the fitting data are simultaneously analyzed with two models: the classical Thomas model (Eq. S7) and empirical Yan model (Eq. S8b) to predict the dynamic breakthrough curves of $\mathrm{Cr}(\mathrm{VI})$ sorption under different flow rates; associated parameters are listed in Table S8. Taking the determination coefficient $\left(R^{2}\right)$ and the AIC into account, the Yan model shows a better fitting of breakthrough profiles than the
Thomas equation. Actually, the Yan model was precisely designed to minimize the error caused by Thomas model, especially at very low or high time periods of the breakthrough curve (Yan et al., 2001). In Thomas model, $\mathrm{K}_{\mathrm{T}}$ represents the reaction rate constant, here, the $\mathrm{K}_{\mathrm{T}}$ values of both sorbents rise with increased flow rate and similar variation tendency was also observed by Yan et al. (2017b). In Yan model, the coefficient of $\mathrm{a}^{\mathrm{Y}}$ represents the slope of breakthrough curve, which relates to the retention rate of loaded sorbents to the fed $\mathrm{Cr}(\mathrm{VI})$, and high $\mathrm{a}^{\mathrm{Y}}$ indicates strong capability of sorbents for binding $\mathrm{Cr}(\mathrm{VI})$ ions ( $\mathrm{Li}$ et al., 2016).

\subsection{Proposed mechanisms of $\operatorname{Cr}(V I)$ sorption}

To gain detailed insights into the mechanisms of $\mathrm{Cr}(\mathrm{VI})$ sorption onto Q-APEI beads, SEM-EDS, FT-IR and XPS analyses were applied to provide complementary evidences. SEM analysis shows both the surface and cross-section observations while EDS spectra gives the distribution of the main elements of Q-APEI beads before and after $\mathrm{Cr}(\mathrm{VI})$ sorption under different $\mathrm{pH}$ values (i.e., $\mathrm{pH} \mathrm{2,} 4$ and 6). As revealed in Fig. 5, the surface of Q-APEI bead shows a certain level of abrasion after $\mathrm{Cr}(\mathrm{VI})$ sorption at $\mathrm{pH} 2$. On one hand, it is partially caused by the continuously shaking process, on the other hand, the binding of $\mathrm{Cr}(\mathrm{VI})$ species with functional groups of Q-APEI (externally or internally) may break the homogeneous structure of Q-APEI bead. Whereas after $\mathrm{Cr}(\mathrm{VI})$ sorption, the cross-section micrographs show that the internal pore structure of QAPEI bead are barely altered compared with original Q-APEI bead.

FT-IR spectra (as shown in Figure S8) reveal the functional groups and chemical bonds of sorbents. The surface of APEI bead bears various functional groups characterized by several specific bands representing the following vibrations: $-\mathrm{OH}$ stretching $\left(3269 \mathrm{~cm}^{-1}\right.$ ) (Zhang et al., 2018), C-H bending (2919 $\mathrm{cm}^{-1}$ ) (Zhang et al., 2013), N-H bending (1591 $\mathrm{cm}^{-1}$ ) (Lindén et al., 2015), -COO- symmetric stretching (1405 $\mathrm{cm}^{-1}$ ) (Zhao et al., 2015), and C-O stretching $\left(1028 \mathrm{~cm}^{-1}\right.$ ) (Dong et al., 2011), which may be highly protonated at low $\mathrm{pH}$ value. After quaternization of APEI, the appearance of the peak at $1472 \mathrm{~cm}^{-1}$ confirms the successful grafting of quaternary ammonium group (Elwakeel, 2010). Afterwards, in the spectrum of Cr-loaded Q-APEI (after $\mathrm{Cr}(\mathrm{VI})$ sorption at $\mathrm{pH}$ 2), new peaks of $803 \mathrm{~cm}^{-1}$ and $518 \mathrm{~cm}^{-1}$ appear in the spectra, which are assigned to the stretching vibrations of $\mathrm{Cr}-\mathrm{O}$ and $\mathrm{Cr}-\mathrm{N}$, respectively (El-Medani et al., 2005). These results (summarized in Table S9) confirm the fundamental reaction of protonated carboxyl
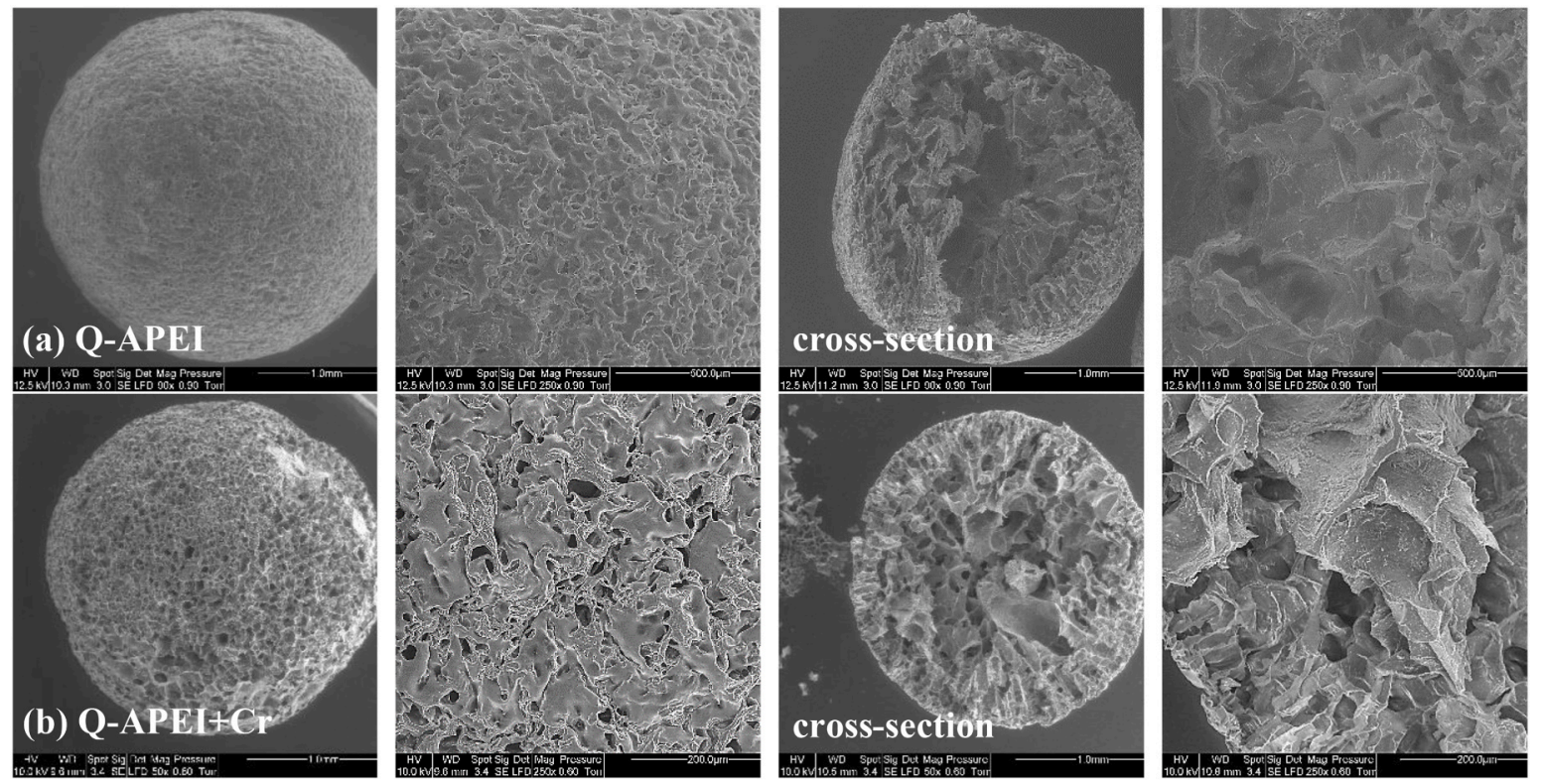

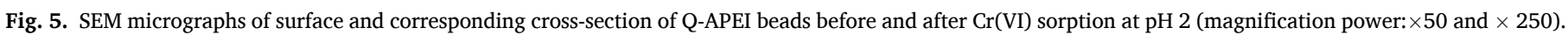


group and nitrogen-based groups (i.e., quaternary ammonium group and amine group) in $\mathrm{Cr}(\mathrm{VI})$ sorption, either through the formation of $\mathrm{Cr}(\mathrm{VI})$ complexes on the sorbent (Eqs. (6) and (7)), or through the electrostatic repulsion to release reduced $\mathrm{Cr}(\mathrm{III})$ into aqueous solution.

$\mathrm{COO}^{-}+\mathrm{H}^{+}+\mathrm{Cr}_{2} \mathrm{O}_{7}^{2-} \rightarrow \mathrm{COOH}^{+}-\mathrm{Cr}$

$\mathrm{NH}_{2}+\mathrm{H}^{+}+\mathrm{Cr}_{2} \mathrm{O}_{7}^{2-} \rightarrow \mathrm{NH}_{3}^{+}-\mathrm{Cr}$

The information about the bonding environment of Q-APEI reactive groups after $\mathrm{Cr}(\mathrm{VI})$ sorption was explored by XPS technique. Fig. 6 shows the XPS survey of sorbent after being loaded with two different chromate concentrations (i.e., 100 and $200 \mathrm{mg} \mathrm{Cr} \mathrm{L}{ }^{-1}$ ). The highest concentration allows saturating the sorbent (see sorption isotherm, in Fig. 2). The sorption of chromium is confirmed by the presence of peaks corresponding to $\mathrm{Cr} 3 p$ (at binding energy, $\mathrm{BE} \sim 43.4 \mathrm{eV}), \mathrm{Cr} 3 s(\sim 74.9$ $\mathrm{eV}), \mathrm{Cr} 2 p(\sim 576.3 \mathrm{eV})$, and $\mathrm{Cr} 2 s(\sim 698.1 \mathrm{eV})$. It is noteworthy that the $\mathrm{Cl} 2 p$ signal appearing at $\mathrm{BE} \sim 197 \mathrm{eV}$ almost disappears at the highest chromium concentration. This probably means that the sorption mechanism involves a mechanism of anionic exchange between chloride ions bound to protonated amine groups of PEI and chromate anions.

The High-Resolution (HRES) XPS spectra are reported in Table S10 for $\mathrm{C} 1 s, \mathrm{O} 1 s, \mathrm{~N} 1 s, \mathrm{Cr} 2 p_{3 / 2}$ and $\mathrm{Cl} 2 p$ (the analysis for $\mathrm{C}_{0}: 200 \mathrm{mg} \mathrm{Cr} \mathrm{L}^{-1}$ is not shown because of the very weak intensity of the signal). Table S11 summarizes for the two loaded sorbents the $\mathrm{BE}(\mathrm{eV})$, atomic fraction (AF, \%) and assignments of these signals. The comparison of the BEs values shows a remarkably stable position of the main bands. In most cases, the variation of the BEs is less than $0.3 \mathrm{eV}$. The largest differences are observed for $\mathrm{Cl} 2 p$ signals; however, the weak signal observed at $\mathrm{C}_{0}$ : $200 \mathrm{mg} \mathrm{Cr} \mathrm{L}{ }^{-1}$ introduces analytical inaccuracies. The assignments of these peaks based on literature highlight the possibility of overlapping of contributions of different bonding types for $\mathrm{C} 1 s, \mathrm{O} 1 s$ and $\mathrm{N} 1 s$ signals (due to the coexistence of many different reactive groups associated with the diversity of sorbent precursors, algal biomass, alginate and PEI). Therefore, it is difficult assigning the variation to the intensities (i.e., AF) to specific interactions. The reduction phenomena is confirmed by the co-existence of two $\mathrm{Cr} 2 p_{3 / 2}$ peaks at $\sim 576.8 \mathrm{eV}$ ( $\mathrm{Cr}-\mathrm{O}$ bond involving $\mathrm{Cr}(\mathrm{III})$ ) and $\sim 578.3 \mathrm{eV}$ (Cr(VI)-O bond) (Bandara et al., 2020). The relative fractions of $\mathrm{Cr}(\mathrm{III})$ and $\mathrm{Cr}(\mathrm{VI})$ are close to $74 \%$ and $26 \%$, respectively, which are in similar with previous report (Xu et al., 2019). This means that chromate ions are strongly reduced on the sorbent surface. This reduction mechanism supposes that functional groups on the sorbent surface are concomitantly oxidized during the sorption/reduction process of chromate anions. Due to the coexistence of many different bonds, and the weak variations in the BEs, the chemical modifications of these functional groups are difficultly detectable. The relative AFs may suggest some trends based on the increase in the intensity of the signal at $\mathrm{BE} \sim 531.4 \mathrm{eV}$ (possibly assigned to $\mathrm{C}=\mathrm{O}$ and $\mathrm{O}-\mathrm{Cr}$ ): the oxidation of some aldehyde groups may increase the relative

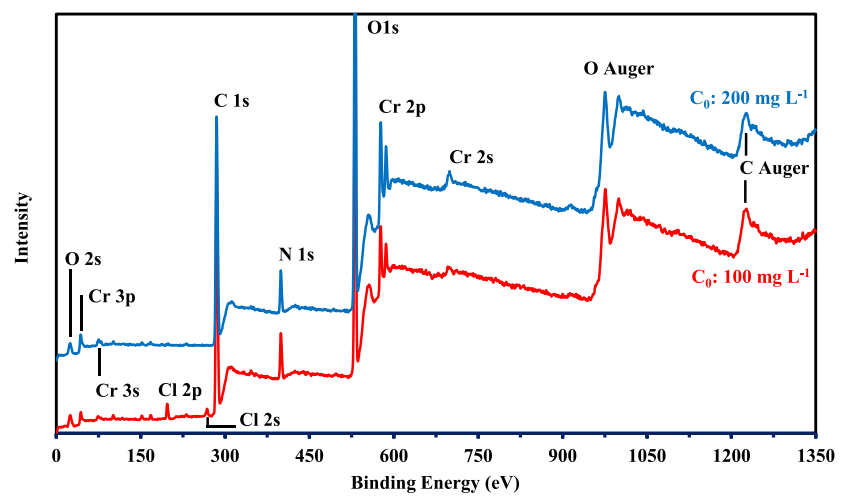

Fig. 6. HRES XPS survey of Q-APEI beads after Cr(VI) sorption at two metal concentrations (i.e., $100 \mathrm{mg} \mathrm{Cr} \mathrm{L}^{-1}$ and $200 \mathrm{mg} \mathrm{Cr} \mathrm{L}^{-1}$ ). fraction of carbonyl groups. The sorption of increasing amounts of chromate anions (including their reduced form) can also explain the increasing contribution of $\mathrm{O}-\mathrm{Cr}$ signal. The intensity of the peak at $\sim 402.0 \mathrm{eV}$ (assigned to protonated amine groups; i.e., $\mathrm{NH}_{3}^{+}$) decreases with increasing metal sorption; combined with the loss of $\mathrm{Cl} 2 p$ signal, this means that electrostatic attraction/ion exchange is involved in metal sorption $\left(\mathrm{Cl}^{-} \leftrightarrow\right.$ chromate anions).

Taking above results into account, the complete mechanism of $\mathrm{Cr}(\mathrm{VI})$ sorption onto quaternized algal/alginate@PEI (Q-APEI) beads may involve ionic (complexation or reduction) interactions between $\mathrm{Cr}(\mathrm{VI})$ ions and the surface functional groups of Q-APEI. In terms of kinetic approach, primarily $\mathrm{Cr}(\mathrm{VI})$ ions transfer from bulk solution across the liquid film surrounding Q-APEI bead, then get to the internal surfaces of Q-APEI through intraparticle diffusion (pore or surface diffusion), under the effect of concentration gradient. Once the $\mathrm{Cr}(\mathrm{VI})$ ions arrived at the Q-APEI surface, the proper sorption mechanism is involved for immobilizing the metal ions. However, this mechanism may be complex due to the coexistence of different reactive groups, the possibility to get some changes in the speciation of the metal, including reduction phenomena. Previous studies reported a combined mechanism in the case of $\mathrm{Cr}(\mathrm{VI})$ sorption (Park et al., 2007; Barrera-Díaz et al., 2012), more specifically the so-called reduction-coupled sorption.

In this study, the oxyanions chromate represent the most predominant of chromium species in aqueous solution, which prefers to combine with the highly protonated nitrogen-type groups (i.e., amine group and quaternary ammonium group) at low $\mathrm{pH}$ (i.e., $\mathrm{pH}$ 2). As proposed in Fig. 7, after contacting with sorbents, some of them will be directly reduced by the electron-donor groups (i.e., hydroxyl groups) on the QAPEI surface, while some may be bound with positively-charged groups then be indirectly reduced by the adjacent electron-donor groups; given the evidence of the large amounts of $\mathrm{Cr}$ (III) detected in the solution and the high fraction of $\mathrm{Cr}$ (III)-O confirmed at the surface of Q-APEI. In this study, there are three assumptions regarding the fate of reduced cationic $\mathrm{Cr}(\mathrm{III})$ species (e.g., $\mathrm{Cr}^{3+}, \mathrm{Cr}(\mathrm{OH})_{2}^{+}$or $\mathrm{Cr}(\mathrm{OH})^{2+}$ ):

(i) be released into the aqueous solution via electronic repulsion by the positively charged groups,

(ii) still be bound with other Cr-binding groups on sorbent surface (Duranoğlu and Beker, 2015), or

(iii) be retained in the internal porous structure of sorbent. However, the distributions of $\mathrm{Cr}(\mathrm{III})$ species in solid and liquid phases are strongly affected by the experimental conditions of sorption (i.e., $\mathrm{pH}$, temperature and $\mathrm{Cr}(\mathrm{VI})$ concentration) and the material (i.e., species of reactive groups and dosage), which remains to be further explored.

\section{Conclusion}

In this work, quaternized algal/alginate@PEI composite beads are successfully prepared and applied to boost $\mathrm{Cr}(\mathrm{VI})$ sorption capacity and its reduction rate (compared with original APEI beads). Different mechanisms of $\mathrm{Cr}(\mathrm{VI})$ reduction-coupled sorption are proposed in this study, which are supported by several methods of characterization. Especially in the discussion of complex mechanisms of $\mathrm{Cr}(\mathrm{VI})$ reduction, this paper spreads out academic study from two aspects at the same time. On one hand, this paper discusses the differential concentrations of $\mathrm{TCr}$ and $\mathrm{Cr}(\mathrm{VI})$ in aqueous solution (for distinguishing $\mathrm{Cr}(\mathrm{VI}) / \mathrm{Cr}(\mathrm{III})$ removal profiles), on the other hand, it analyses the fractions of $\mathrm{Cr}(\mathrm{VI})$ and Cr(III) bound on Q-APEI surface. The XPS analysis reveals that after chromate binding onto Q-APEI, the $\mathrm{Cr}(\mathrm{III})$ species may be partially released into aqueous solution while another significant part remains on the Q-APEI surface, therefore enhancing the sorption capacity of chromate and the global removal of $\mathrm{Cr}(\mathrm{VI})$.

Thus, the main conclusions of this work consist of: 


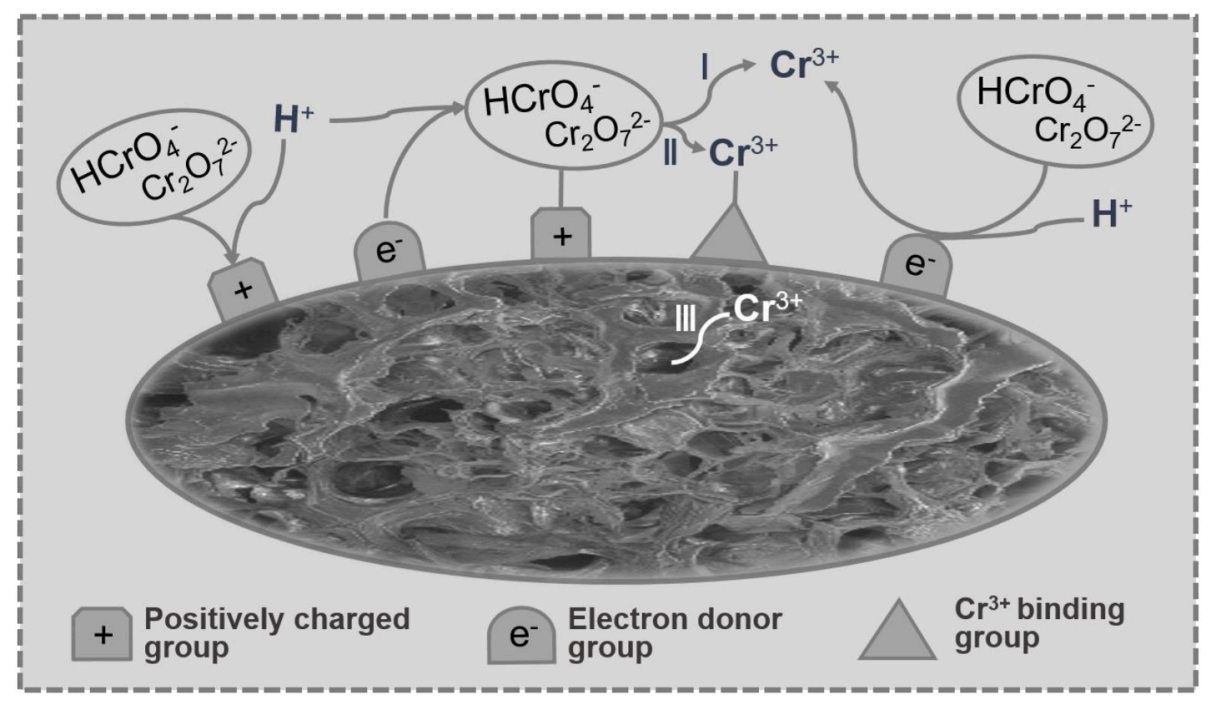

Fig. 7. Proposed mechanism of Cr(VI) sorption by Q-APEI beads.

(a) at optimal $\mathrm{pH} 2$, the oxyanions chromate tends to be removed from the aqueous system through the combination with the protonated groups, the ion-exchange reaction with chloride anions on quaternary ammonium group and the reduction to $\mathrm{Cr}$ (III) species by the electron donor at sorbent surface.

(b) in the batch study of sorption behavior, the sorption isotherm is fitted by the Sips model meanwhile the maximal sorption capacity approaches to $334 \mathrm{mg} \mathrm{Cr}(\mathrm{VI}) \mathrm{g}^{-1}$, including a rate of chromate reduction close to $25 \%$.

(c) in the fixed-bed process with recirculation mode, the sorption kinetics is described by the pseudo-second order rate equation (PSORE), while the intraparticle diffusion plays a significant part in the overall control of kinetics.

(d) in the fixed-bed process with single path mode, the breakthrough curves of Q-APEI were successfully fitted by the Yan model (better than the Thomas model).

(e) Q-APEI beads were capable of maintaining good stability for at least 3 cycles of sorption-desorption reuse.

This work completes previous investigations on Q-APEI for the removal of other metals, for illustrating the specific impact of metal ions having a high potential for reduction. Overall, the prospects look bright for the further use of this quaternary-functionalized sorbent and continues to be a great impetus to research efforts to discover or to optimize new algal/alginate-based PEI-crosslinked materials.

Moreover, the comprehensive research concerning chromium sorption on the batch process and column process with different reflux modes (i.e., single path and recirculation) provides an experimental reference in detail for future industrial applications.

\section{Credit author statement}

Yue ZHENG: Conceptualization, Software, Formal analysis, Investigation, Writing - original draft, Visualization, Funding acquisition; Yayuan MO: Conceptualization, Validation; Thierry VINCENT: Conceptualization, Investigation; Catherine FAUR: Validation, Data curation, Supervision, Writing - review \& editing; Eric GUIBAL: Conceptualization, Methodology, Software, Formal analysis, Resources, Data curation, Writing - review \& editing, Project administration, Funding acquisition.

\section{Declaration of competing interest}

The authors declare that they have no known competing financial interests or personal relationships that could have appeared to influence the work reported in this paper.

\section{Acknowledgements}

Y. Zhang acknowledges the China Scholarship Council (CSC, Grant $\mathrm{N} \circ 201906660008$ ) for providing PhD fellowship. Authors thank JeanClaude Roux (IMT Mines Alès, C2MA) for his technical support for SEM and SEM-EDX analyses. Authors thank Mohammed F. Hamza (Nuclear Materials Authority, Egypt) for his technical support for XPS analyses.

\section{Appendix A. Supplementary data}

Supplementary data to this article can be found online at https://doi. org/10.1016/j.chemosphere.2021.130844.

\section{References}

Ahmad, M., Zhang, B., Wang, J., Xu, J., Manzoor, K., Ahmad, S., Ikram, S., 2019. New method for hydrogel synthesis from diphenylcarbazide chitosan for selective copper removal. Int. J. Biol. Macromol. 136, 189-198.

Ajmani, A., Shahnaz, T., Narayanan, S., Narayanasamy, S., 2019. Equilibrium, kinetics and thermodynamics of hexavalent chromium biosorption on pristine and zinc chloride activated Senna siamea seed pods. Chem. Ecol. 35, 379-396.

Al-Ghouti, M.A., Da'ana, D.A., 2020. Guidelines for the use and interpretation of adsorption isotherm models: a review. J. Hazard Mater. 393. Art. No 122383.

Altun, T., Parlayıcı, Ş., Pehlivan, E., 2016. Hexavalent chromium removal using agricultural waste "rye husk". Desalin. Water Treat. 57, 17748-17756.

Arim, A.L., Quina, M.J., Gando-Ferreira, L.M., 2019. Uptake of trivalent chromium from aqueous solutions by xanthate pine bark: characterization, batch and column studies. Process Saf. Environ. Protect. 121, 374-386.

Arris, S., Lehocine, M.B., Meniai, A.-H., 2016. Sorption study of chromium sorption from wastewater using cereal by-products. Int. J. Hydrogen Energy 41, 10299-10310.

Ayers, P.W., 2005. An Elementary Derivation of the Hard/soft-Acid/base Principle. AIP.

Bandara, P., Peña-Bahamonde, J., Rodrigues, D., 2020. Redox mechanisms of conversion of $\mathrm{Cr}(\mathrm{VI})$ to $\mathrm{Cr}$ (III) by graphene oxide-polymer composite. Sci. Rep. 10, 1-8.

Barrera-Díaz, C.E., Lugo-Lugo, V., Bilyeu, B., 2012. A review of chemical, electrochemical and biological methods for aqueous $\mathrm{Cr}(\mathrm{VI})$ reduction. J. Hazard Mater. 223-224, 1-12.

Bonilla-Petriciolet, A., Mendoza-Castillo, D.I., Reynel-Ávila, H.E., 2017. Adsorption Processes for Water Treatment and Purification. Springer.

Deng, S., Bai, R.B., 2003. Aminated polyacrylonitrile fibers for humic acid adsorption: behaviors and mechanisms. Environ. Sci. Technol. 37, 5799-5805.

Dong, G., Wang, Y., Gong, L., Wang, M., Wang, H., He, N., Zheng, Y., Li, Q., 2013. Formation of soluble $\mathrm{Cr}(\mathrm{III})$ end-products and nanoparticles during $\mathrm{Cr}(\mathrm{VI})$ reduction by Bacillus cereus strain XMCr-6. Biochem. Eng. J. 70, 166-172.

Dong, X., Ma, L.Q., Li, Y., 2011. Characteristics and mechanisms of hexavalent chromium removal by biochar from sugar beet tailing. J. Hazard Mater. 190, 909-915.

Duranoğlu, D., Beker, U., 2015. Cr(VI) adsorption onto biomass waste material-derived activated carbon. Desalination Updates, Art. N 273. 
El-Medani, S.M., Ali, O.A., Ramadan, R.M., 2005. Photochemical reactions of group 6 metal carbonyls with $\mathrm{N}$-salicylidene-2-hydroxyaniline and bis-(salicylaldehyde) phenylenediimine. J. Mol. Struct. 738, 171-177.

Elwakeel, K.Z., 2010. Removal of Cr(VI) from alkaline aqueous solutions using chemically modified magnetic chitosan resins. Desalination 250, 105-112.

Fang, J., Gu, Z., Gang, D., Liu, C., Ilton, E.S., Deng, B., 2007. Cr(VI) removal from aqueous solution by activated carbon coated with quaternized poly(4-vinylpyridine) Environ. Sci. Technol. 41, 4748-4753.

Fenti, A., Chianese, S., Iovino, P., Musmarra, D., Salvestrini, S., 2020. Cr(VI) sorption from aqueous solution: a review. Appl. Sci. 10. Art. № 6477.

Gorny, J., Billon, G., Noiriel, C., Dumoulin, D., Lesven, L., Madé, B., 2016. Chromium behavior in aquatic environments: a review. Environ. Rev. 24, 503-516.

Gupta, V., Agarwal, A., Singh, M., Singh, N., 2017. Removal of red RB dye from aqueous solution by belpatra bark charcoal (BBC) adsorbent. J. Mater. Environ. Sci. 8, 3654-3665.

Hamza, M.F., Lu, S., Salih, K.A.M., Mira, H., Dhmees, A.S., Fujita, T., Wei, Y., Vincent, T. Guibal, E., 2020a. As(V) sorption from aqueous solutions using quaternized algal/ polyethyleneimine composite beads. Sci. Total Environ. 719. Art. $N^{\circ} 137396$.

Hamza, M.F., Mubark, A.E., Wei, Y., Vincent, T., Guibal, E., 2020b. Quaternization of composite algal/PEI beads for enhanced uranium sorption-application to ore acidic leachate. Gels 6. Art. N 12 .

Hamza, M.F., Wei, Y., Guibal, E., 2020c. Quaternization of algal/PEI beads (a new sorbent): characterization and application to scandium sorption from aqueous solutions. Chem. Eng. J. 383. Art. N 123210.

Hubbe, M.A., Azizian, S., Douven, S., 2019. Implications of apparent pseudo-secondorder adsorption kinetics onto cellulosic materials: a review. BioResources 14, 7582-7626.

Inglezakis, V.J., Poulopoulos, S.G., Kazemian, H., 2018. Insights into the S-shaped sorption isotherms and their dimensionless forms. Microporous Mesoporous Mater. 272, 166-176.

Jobby, R., Jha, P., Yadav, A.K., Desai, N., 2018. Biosorption and biotransformation of hexavalent chromium [Cr(VI)]: a comprehensive review. Chemosphere 207, $255-266$.

Kumar, S., Shahnaz, T., Selvaraju, N., Rajaraman, P.V., 2020. Kinetic and thermodynamic studies on biosorption of $\mathrm{Cr}(\mathrm{VI})$ on raw and chemically modified Datura stramonium fruit. Environ. Monit. Assess. 192. Art. N 248.

Li, L., Li, Y., Yang, C., 2016. Chemical filtration of Cr(VI) with electrospun chitosan nanofiber membranes. Carbohydr. Polym. 140, 299-307.

Lindén, J.B., Larsson, M., Kaur, S., Skinner, W.M., Miklavcic, S.J., Nann, T., Kempson, I. M., Nydén, M., 2015. Polyethyleneimine for copper absorption II: kinetics, selectivity and efficiency from seawater. RSC Adv. 5, 51883-51890.

Liu, X., Zhang, H., Luo, Y., Zhu, R., Wang, H., Huang, B., 2020. Sorption of oxytetracycline in particulate organic matter in soils and sediments: roles of $\mathrm{pH}$, ionic strength and temperature. Sci. Total Environ. 714. Art. N 136628.

Miretzky, P., Cirelli, A.F., 2010. Cr(VI) and Cr(III) removal from aqueous solution by raw and modified lignocellulosic materials: a review. J. Hazard Mater. 180, 1-19.

Mo, Y., Wang, S., Vincent, T., Desbrieres, J., Faur, C., Guibal, E., 2019. New highlypercolating alginate-PEI membranes for efficient recovery of chromium from aqueous solutions. Carbohydr. Polym. 225. Art. N 115177.

Mungasavalli, D.P., Viraraghavan, T., Jin, Y.-C., 2007. Biosorption of chromium from aqueous solutions by pretreated Aspergillus nigerr: batch and column studies. Colloids Surf. A Physicochem. Eng. Asp. 301, 214-223.

N'diaye, A.D., Bollahi, M.A., Kankou, M., 2019. Sorption of paracetamol from aqueous solution using groundnut shell as a low cost sorbent. J. Mater. Environ. Sci. 10, $553-562$.

Park, D., Lim, S.R., Yun, Y.S., Park, J.M., 2007. Reliable evidences that the removal mechanism of hexavalent chromium by natural biomaterials is adsorption-coupled reduction. Chemosphere 70, 298-305.

Park, D., Yun, Y.S., Park, J.M., 2005. Studies on hexavalent chromium biosorption by chemically-treated biomass of Ecklonia sp. Chemosphere 60, 1356-1364.

Pholosi, A., Naidoo, E.B., Ofomaja, A.E., 2020. Intraparticle diffusion of $\mathrm{Cr}$ (VI) through biomass and magnetite coated biomass: a comparative kinetic and diffusion study. S. Afr. J. Chem. 32, 39-55.

Pradhan, D., Sukla, L.B., Sawyer, M., Rahman, P.K., 2017. Recent bioreduction of hexavalent chromium in wastewater treatment: a review. J. Ind. Eng. Chem. 55, $1-20$.

Saadi, R., Saadi, Z., Fazaeli, R., Fard, N.E., 2015. Monolayer and multilayer adsorption isotherm models for sorption from aqueous media. Kor. J. Chem. Eng. 32, 787-799.

Saha, B., Orvig, C., 2010. Biosorbents for hexavalent chromium elimination from industrial and municipal effluents. Coord. Chem. Rev. 254, 2959-2972.
Saha, R., Nandi, R., Saha, B., 2011. Sources and toxicity of hexavalent chromium. J. Coord. Chem. 64, 1782-1806.

Shanab, S., Essa, A., Shalaby, E., 2012. Bioremoval capacity of three heavy metals by some microalgae species (Egyptian Isolates). Plant Signal. Behav. 7, 392-399.

Simonin, J.-P., 2016. On the comparison of pseudo-first order and pseudo-second order rate laws in the modeling of adsorption kinetics. Chem. Eng. J. 300, 254-263.

Sun, X.-F., Ma, Y., Liu, X.-W., Wang, S.-G., Gao, B.-Y., Li, X.-M., 2010. Sorption and detoxification of chromium(VI) by aerobic granules functionalized with polyethylenimine. Water Res. 44, 2517-2524.

Szabó, L., Gerber-Lemaire, S., Wandrey, C., 2020. Strategies to functionalize the anionic biopolymer Na-alginate without restricting its polyelectrolyte properties. Polymers 12. Art. $\mathrm{N}^{\circ} 919$.

Tang, P., Lee, C., Low, K., Zainal, Z., 2003. Sorption of $\mathrm{Cr}(\mathrm{VI})$ and $\mathrm{Cu}(\mathrm{II})$ in aqueous solution by ethylenediamine modified rce hull. Environ. Sci. Technol. 24, 1243-1251.

Tekay, E., Aydınoğlu, D., Șen, S., 2019. Effective adsorption of Cr(VI) by high strength chitosan/montmorillonite composite hydrogels involving spirulina biomass/ microalgae. J. Polym. Environ. 27, 1828-1842.

Tian, X., Wang, W., Wang, Y., Komarneni, S., Yang, C., 2015. Polyethylenimine functionalized halloysite nanotubes for efficient removal and fixation of $\mathrm{Cr}(\mathrm{VI})$. Microporous Mesoporous Mater. 207, 46-52.

Wang, S., Vincent, T., Faur, C., Guibal, E., 2016. Alginate and algal-based beads for the sorption of metal cations: $\mathrm{Cu}(\mathrm{II})$ and $\mathrm{Pb}(\mathrm{II})$. Int. J. Mol. Sci. 17. Art. N ${ }^{\circ} 1453$.

Wang, S., Vincent, T., Faur, C., Rodríguez-Castellón, E., Guibal, E., 2019. A new method for incorporating polyethyleneimine (PEI) in algal beads: high stability as sorbent for palladium recovery and supported catalyst for nitrophenol hydrogenation. Mater. Chem. Phys. 221, 144-155.

Wei, Y., Salih, K.A., Lu, S., Hamza, M.F., Fujita, T., Vincent, T., Guibal, E., 2019. Amidoxime functionalization of algal/polyethyleneimine beads for the sorption of Sr (II) from aqueous solutions. Molecules 24. Art. $\mathrm{N}^{\circ} 3893$.

Wei, Y., Salih, K.A.M., Rabie, K., Elwakeel, K.Z., Zayed, Y.E., Hamza, M.F., Guibal, E., 2021. Development of phosphoryl-functionalized algal-PEI beads for the sorption of $\mathrm{Nd}(\mathrm{III})$ and $\mathrm{Mo}(\mathrm{VI})$ from aqueous solutions - application for rare earth recovery from acid leachates. Chem. Eng. J. 412. Art. N 127399.

Xia, S., Song, Z., Jeyakumar, P., Shaheen, S.M., Rinklebe, J., Ok, Y.S., Bolan, N., Wang, H., 2019. A critical review on bioremediation technologies for $\mathrm{Cr}(\mathrm{VI})$ contaminated soils and wastewater. Crit. Rev. Environ. Sci. Technol. 49, 1027-1078.

Xu, X., Huang, H., Zhang, Y., Xu, Z., Cao, X., 2019. Biochar as both electron donor and electron shuttle for the reduction transformation of $\mathrm{Cr}(\mathrm{VI})$ during its sorption. Environ. Pollut. 244, 423-430.

Yakout, S.M., Elsherif, E., 2010. Batch kinetics, isotherm and thermodynamic studies of adsorption of strontium from aqueous solutions onto low cost rice-straw based carbons. Carbon - Sci. Tech. 3, 144-153.

Yan, G., Viraraghavan, T., Chen, M., 2001. A new model for heavy metal removal in a biosorption column. Adsorpt. Sci. Technol. 19, 25-43.

Yan, Y.-Z., An, Q.-D., Xiao, Z.-Y., Zhai, S.-R., Zhai, B., Shi, Z., 2017a. Interior multicavity/surface engineering of alginate hydrogels with polyethylenimine for highly efficient chromium removal in batch and continuous aqueous systems. J. Mater. Chem. 5, 17073-17087.

Yan, Y., An, Q., Xiao, Z., Zheng, W., Zhai, S., 2017b. Flexible core-shell/bead-like alginate@PEI with exceptional adsorption capacity, recycling performance toward batch and column sorption of $\mathrm{Cr}(\mathrm{VI})$. Chem. Eng. J. 313, 475-486.

Zhang, H., Yue, X., Li, F., Xiao, R., Zhang, Y., Gu, D., 2018. Preparation of rice strawderived biochar for efficient cadmium removal by modification of oxygen-containing functional groups. Sci. Total Environ. 631, 795-802.

Zhang, S., Lyu, H., Tang, J., Song, B., Zhen, M., Liu, X., 2019. A novel biochar supported CMC stabilized nano zero-valent iron composite for hexavalent chromium removal from water. Chemosphere 217, 686-694.

Zhang, Y., Jiao, X., Liu, N., Lv, J., Yang, Y., 2020. Enhanced removal of aqueous Cr(VI) by a green synthesized nanoscale zero-valent iron supported on oak wood biochar. Chemosphere 245. Art. No 125542.

Zhang, Z.-b., Cao, X.-h., Liang, P., Liu, Y.-h., 2013. Adsorption of uranium from aqueous solution using biochar produced by hydrothermal carbonization. J. Radioanal. Nucl. Chem. 295, 1201-1208.

Zhao, W., Yuan, P., She, X., Xia, Y., Komarneni, S., Xi, K., Che, Y., Yao, X., Yang, D., 2015. Sustainable seaweed-based one-dimensional (1D) nanofibers as highperformance electrocatalysts for fuel cells. J. Mater. Chem. 3, 14188-14194.

Zyoud, A.H., Zubi, A., Zyoud, S.H., Hilal, M.H., Zyoud, S., Qamhieh, N., Hajamohideen, A., Hilal, H.S., 2019. Kaolin-supported ZnO nanoparticle catalysts in self-sensitized tetracycline photodegradation: zero-point charge and $\mathrm{pH}$ effects. Appl. Clay Sci. 182. Art. N ${ }^{\circ} 105294$. 